\title{
DESENVOLVIMENTO DE MODELO PARA SIMULAÇÃO DA PROGRESSÃO DE DOENÇAS DE PLANTAS
}

\author{
NEWTON DE CASTRO FEGIES \\ Engenheiro Agrônomo
}

Orientador: ARMANDO BERGAMIN FILHO

Dissertação apresentada à Escola Superior de Agricultura "Luiz de Queiroz", da Universidade de São Paulo, para obtenção do título de Mestre em Agronomia. Área de Concentração: Fitopatologia.

$P \mid R A C I C A B A$

Estado de São Paulo - Brasil

Abril, 1985 
. i i i .

A meus pais,

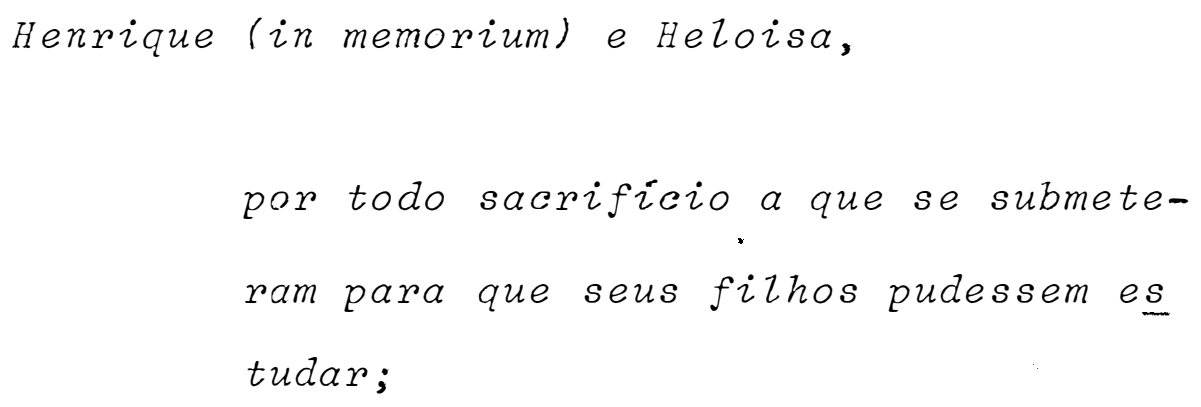

A minha esposa, Silvia e a meus filhos, Juliana e Thiago,

pelas horas de convivio a que nos pri vamos durante a realizasão deste trabalho; 


\section{AGRADEC IMENTOS}

A realização deste trabalho foi decorrência da colaboração direta ou indireta de muitas pessoas, nu ma demonstração inequívoca de que o ser humano necessita vi ver em sociedade.

Agradeço em particular:

- Ao professor Dr. Armando Bergamin Filho, por seu incentivo como orientador, desde a graduação, na área de epidemiologia e de cujo otimismo permanente muito me beneficiei .

- Aos professores do Departamento de Fitopatologia da Escola Superior de Agricultura "Luiz de Queiroz" da Universidade de São Paulo, de cujo conhecimentos e dedicação devo minha formação na área de Fitopatologia.

- Ao Professor Dr. Hiroshi Kimati, em especial, por sua eterna disponibilidade e boa vontade na orientação dos novatos: 
- Aos colegas do Curso de Pös-Graduação em Fitopatologia, em particular aos integrantes do grupo de epidemiologia, Bea triz J. Mendes e Sergio B. Paiva, pelas horas de estudo em conjunto.

- Aos funcionārios do Departamento de Fitopatologia : da ESALQ.

- Ao Dr. Ricardo B. Sgrillo por sua colaboração no uso do computador do Centro de Energia Nuclear na Agricultura.

- A Fundação de Amparo à Pesquisa do Estado de São Paulo pẹ la bolsa de mestrado.

- A Valdete e a sua equipe pelos cuidados com a datilografia e impressão dos originais. 
.vi.

DESEMVOLVIMENTO DE MODELO PARA SIMULAÇ̃̃O DA PROGRESSÃO DE , DOENGAS DE PLAMTAS

AUTOR: $\quad$ NEWTON DE CASTRO FEGIES

ORIENTADOR: ARMANDO BERGAMIN FILHO

\title{
RESUMO
}

\begin{abstract}
A partir da equação diferencial que descre ve doenças policíclicas proposta por VAN DER PLANK (1963), elaborou-se um modelo de simulação de doenças, incorporando-se a este rotinas que permitem o estudo de diferentes padrões de produção de esporos efetivos.

$$
\text { Epidemias foram simuladas em função dos va }
$$

lores de quantidade de tecido disponível, taxa bäsica de in feção corrigida, período latente e período infeccioso. 0s valores obtidos foram transformados em logito e, por análise de regressão linear, os parâmetros epidemiológicos inôcu lo inicial ( $\left.x_{0}\right)$ e taxa aparente de infecção ( $r$ ) foram calüu lados.
\end{abstract}


A verificação do modelo indicou que o mesmo reproduziu razoavelmente bem os sistemas Phythophthora infestans - batata e Puccinia graminis - trigo.

A simulação do efeito de alterações no pe.ríodo infeccioso, mantendo-se constante todos os outros parâmetros epidemiolögicos, indicou que o mesmo altera o valor da taxa aparente de infeção ( $r$ ) enquanto for menor ou igual ao período latente.

Constatou-se, tambëm, que existe uma relação inversa, de aproximadamente $1: 0,5$, entre variações no período latente e o correspondente efeito na taxa aparente de infecção, indicando a sensibilidade do modelo ao período latente.

Variações na quantidade de tecido disponível dão evidência que existe um limite mínimo a partir do qual o modelo não-.é mais representativo.

Simulações realizadas com quatro padrões de produção de esporos indicaram que o padrão associado às ferrugens temperadas deram origem às maiores taxas aparentes de infeção, vindo logo em seguida as ferrugens tropicais e cujos valores se aproximam dos obtidos com o padrão médio constante durante o período infeccioso. 0 padrão de produção de esporos, assocíada às ferrugens temperadas se caracteriza por ser assimêtrico com mäximo nos primèrros 
. viii.

dias do período infeccioso, enquanto que o relativo às ferrugens tropicais ë irregular com diversos pontos de mäximo relativo. 
.ix.

\title{
DEVELOPMENT OF A MODEL. TO SIMULATE \\ PLANT DISEASES PROERESS
}

\author{
AUTHOR : NEWTON DE CASTRO FEGIES \\ ADVISER: ARMANDO BERGAMIN FILHO
}

\section{SUMMARY}

A simulation model of disease has been made based on a differential equation of compound interest disease (VAN DER PLANK, 1963). Some routines that simulate patterns of effective spore production have been introduced on the model.

Data of the number of available infection site, corrected basic infection rate, latent and infectious period have been employed to simulate epidemics. The logits have been calculated and the epidemics parameter initial inoculum $\left(x_{0}\right)$ and apparent infection rate $(r)$ have been obtained by linear regression analyses, 
The verification of the model showed that the systems Phytophthora infestans - potato and Puccinia graminis - wheat have been reasonably well reproduced. The effects of changes on infectious period have been simulated, keeping constant all the other epidemiological parameters. Changes on the apparent . infection rate have been obtained when the value of the infectious periods were smaller than the value of the latent period.

It has been observed that there is an inverse relation between the latent period an the apparent infection rate. The value of this inverse relation is near $1: 0,5$, and it shows the model sensibility to the latent period.

It has also been observed that the model is not representative when the number of available infection sites get smaller than a minimum value.

Simulations ha:ve been done with four patterns of spore production. The highest apparent infection rate has been obtained by the temperate rust pattern, followed by the tropical rust pattern. This last one has an apparent infection rate a little higher than the constant spore production pattern. Temperate rust pattern is assimetric 
.$x i$.

with maximum spore production on the begining of the infeccions period. Tropical rust pattern is irregular with a lot of maximum relative points. 


\section{N D I C E}

PÁG ,

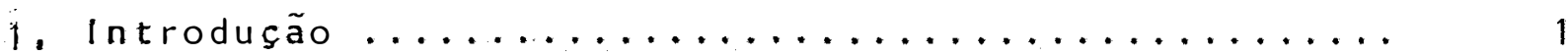

2. Revisão Bibliogräfica .................... 4

2.1. Modelos de simulação de epidemias ............. 4

2.2. Parâmetros monocíclicos .................. 14

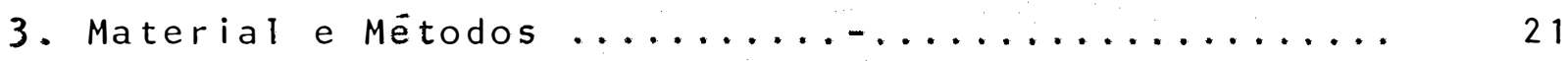

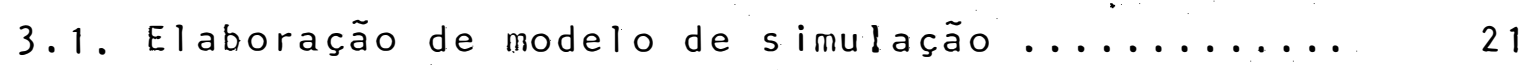

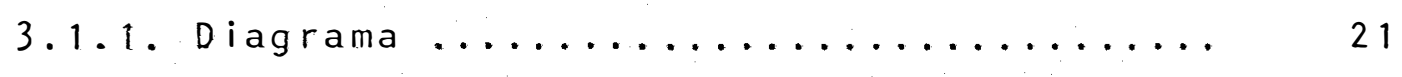

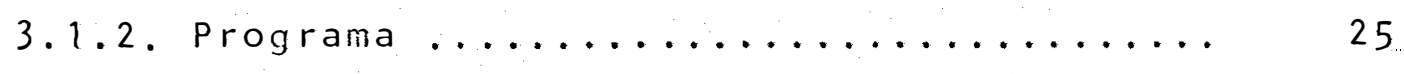

3.2. Verificação do modelo $\ldots \ldots \ldots \ldots \ldots \ldots \ldots \ldots$.

3.3. Simulação do efeito de alterações no periodo in feccioso ........................... 38

3.4. Simulação do efeito de alterações no período la

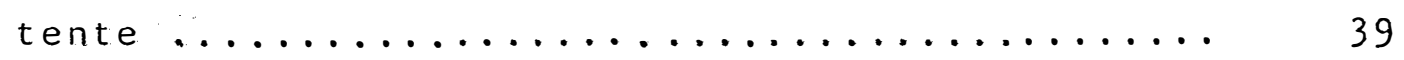

3.5. Simulação do efeito de alterações na quantidade de tecido disponivel .................. 39

3.6. Simulação do efeito de padrões de produção de esporos efetivos ..................... 39

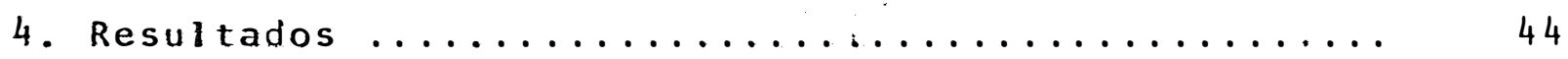

4.1. Verificação do modelo .................. 44

4.2. Simulação do efeito de alterações no período in feccioso ........................... 46

4.3. Simulação do efeito de alterações no período la tente ............................ 50

4.4. Simulação do efeito de al terações na quantidade

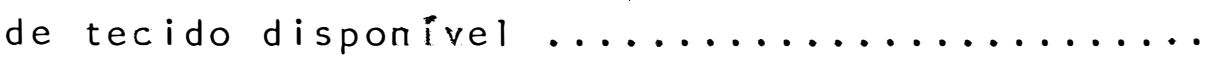

4.5. Simulação do efeito de padrões de produção de es poros com periodo infeccioso de 8 dias. ....... 
. $x \mathrm{i} i \mathrm{i}$

Pảg.

4.6. Simulação do efeito de padrões de produção de esporos com período infeccioso de 25 dias .....

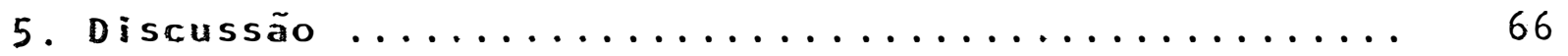

5.1. Elaboração de modelos de simulação .......... 66

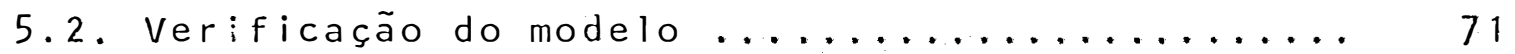

5.3. Simulação do efeito de al terações no período in

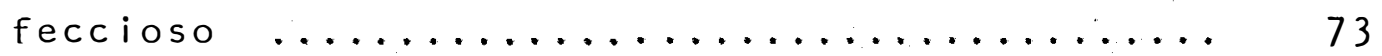

5.4. Simulação do efeito de alterações no período la

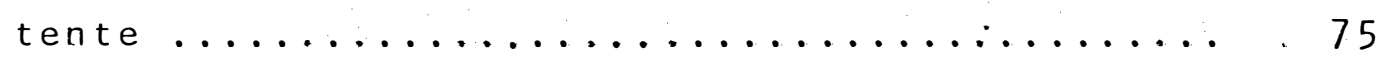

5.5. Simulação do efeito de alterações na quantidade do tecido disponível ................... 77

5.6. Simulação do efeito de padrões de produção de esporos com período infeccioso de 8 e 25 dias.. 80

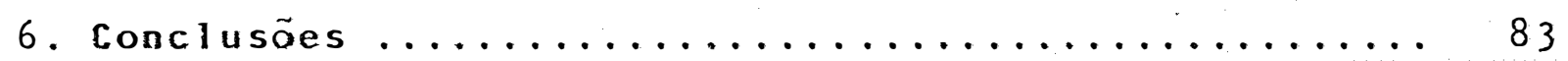

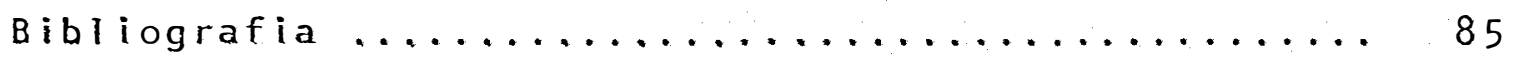

Apêndice $1 \ldots \ldots \ldots \ldots \ldots \ldots \ldots \ldots \ldots \ldots \ldots \ldots \ldots \ldots$

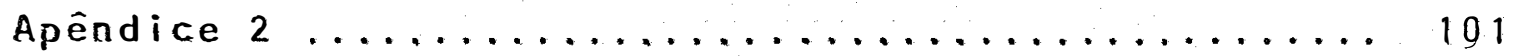




\section{INTRODUÇĀO}

A Fitopatologia, enquanto àrea específica do conhecimento humano, mostra um processo contínuo de evolução. No início estudava-se exclusivamente as característi cas dos agentes fitopatogênicos, num sentido restrito. Nas décadas recentes incorporou-se a análise das interações patögeno, hospedeiro e ambiente. 0 mais novo ramo da fitopato logia, a epidemiologia, agrega o estudo de populações de plantas, de patógenos e as doenças decorrentes, sob influên cia do meio ambiente e do homem. A anälise de sistemas e a matemática fazem parte de seu instrumental na medida em que se observa doença em função do tempo (COWLING e HORSFALL, 1978; GALLI e CARVALHO, 1978; KRANZ, 1974). 


$$
\text { VAN DER PLANK (1963) propos que a varia- }
$$

ção da quantidade de tecido doente no tempo pode ser decrita por modelos matemäticos, por ele designados de juros sim ples e de juros compostos. Doenças que seguem uma dinâmica de juros compostos são também conhecidas como policíclicas na medida em que ocorre diversas gerações do patógeno por ciclo da cultura. o processo policíclico é o resultado de uma série de processos monocíclicos, sendo estes caracterizados, numericamente, pelos parámetros monocíclicos, tais como período latente, período de incubação, período infeccioso, produção de esporos, tipo ou grau de infecção, frequência de infeçãao. o efeito biolögico de alguns desses parâme tros, na evolução de uma epidemia, num modelo de juros compostos, condiciona o valor da taxa bäsica de infecção corri gida, que nada mais é do que o nümero de unidades de tecido doente gerado por unidade original de tecido doente numa unidade de tempo. Assim, ensaios conduzidos em condições con troladas permitem que se obtenham valores de parâmetros monocíclicos, o que pode levar ao estabelecimento de estratégias adequadas para o manejo de doenças (ZADOKS e SCHEIN, 1979 ; FRY, 1982).

A anälise de sistemas entendida como um instirumental para se lidar com situações complexas e o emprego de computador dão condiçoses para que o efeito de cada parâmetro monocíclico da equação de juros compostos possa 
ser simulado e interpretado, ampliando-se, desta forma, o conhecimento das implicações tëcnicas do modelo (ZADOKS,1971; DENT e BLACKIE, 1979).

Assim, o presente trabalho tem por objeti-

vos:

a. Elaborar um modelo de simulação, em computador, de epide mias, que descreva uma dinâmica de doenças de juros compostos;

b. Estudar o comportamento do modelo em decorrência de alte rações nos valores dos parâmetros monocíclicos: período latente, período infeccioso e produção de esporos efetivos, empregando dados obtidos na literatura. 


\section{REVISÃO BIBLIOGRÁFICA}

2. 1. Modelos de simulação de epidemias

Modelos são, talvez, tão velhos quanto o raciocínio científico. Entre um dos primeiros modelos bioló gicos propostos, por exemplo, estä o empregado na classificação de animais e plantas (BATSCHELET, 1966). Um modelo pode ser uma acertiva, uma hipötese, uma teoria ou uma lei (KRANZ, 1974). Um modelo não é uma versão em miniatura de a.lgum sistema real que o reproduzirä perfeitamente. Antes,é uma simplificação da realidade, usualmente enfocando um a $\underline{s}$ pecto particular de um todo, quase sempre de um problema de terminado. Raramente é completo, nunca perfeito e não tem fim em si mesmo. Todo modelo $\vec{e}$ baseado em experiências prë- 
vias e devem ser verificados e melhorados por meio de novas experimentações (KRANZ, 1974; KRANZ e ROYLE, 1978; KRANZ e HAU, 1980).

$$
\text { Um modelo biológico deve satisfazer algu- }
$$

mas condições. Assim ë desejāvel que seja (BATSCHELET, 1966; KRANZ, 1974 ; KRANZ e ROYLE, 1978):

a. Razoavelmente simples e consistentemente lógico;

b. Matematicamente correto e;

c. Capaz de fornecer previsões.

Finalmente é essencial que os modelos tenham um objetivo bem definido e que sejam välidos (KRANZ e ROYLE, 1978 ).

$$
\text { Em epidemiologia, a linguagem matemática }
$$

tem um papel de destaque, pois é o meio mais preciso para expressar a dinâmica dos procéssos biológicos. A matemática, neste caso, pode ser interpretada como um moinho que recebe dados biológicos, à semelhança do que ocorre entre o milho e a farinha. Com esta filosofia, a anälise matemática ê empregada para elaboração de modelos (VAN DER PLANK, 1966).

os modelos empregados em epidemiologia podem ser divididos em: 
a. Descritivos (KRANZ e ROYLE, 1978) - expressam hipōteses ou generalizam resultados experimentais relativos a epidemias, tais como, infecção, inóculo, fatores ambientés, evolução de doença, etc. Estes modelos tem a limitação de somente serem operacionais sob as condições nas quais foram estabelecidos. Por sua natureza eles lidam com taxas mas, normalmente, não revelam os mecanismos geradores dos nümeros obtidos;

b. Preditivos (KRANZ e ROYLE, 1978) ou Exploratōrios (KRANZ e HAU, 1980) - são modelos descritivos cujas variäveis são aval ladas pela capacidade de fornecerem previsões. Nor malmente, são el aborados com equações diferenciais e regressões mültiplas.

c. Conceituais (KRANZ e ROYLE, 1978), Funcionais (BUTT e ROYLE, 1974) ou Sinöpticos (KRANZ e HAU, 1980) - são modelos que propõem representar os mecanismos de funcionamento dos sistemas naturais, podendo ser uma série de sub-modelos reunidos, simulando o todo ou parte do siste ma. Resultam do agrupamento de variäveis matemáticas que procuram englobar as interações e os "feedbacks" que são abundantes nos sistemas ecológicos (ROYLE e BUTT, 1979).

A abordagem matemática na epidemiologia te ve seu início com VAN DER PLANK (1963) que empregou modelus descritivos no tratamento de problemas epidemiológicos. 0 
progresso da doença no tempo foi descrita como um modelo de juros simples, quando a doença aumenta sem que ocorra multi plicação no sentido do patógeno ir de uma lesão para outra, num mesmo ciclo. As doenças de juros compostos seriam aquelas em que lesões filhas são geradas a partir de lesões mães, no mesmo ciclo da cultura (VAN DER PLANK, 1963).

A incorporação de unidades de espaço aos modelos epidemiológicos, que até então eram fundamentados exclusivamente na descrição do progresso da doença em função do tempo, se constitui um dos atuais desafios da epidemiologia (JEGER, 1983).

Considera-se como limitação inerente aos modelos descritivos o fato de se assumir que variáveis inde pendentes agem aditivamente e diretamente como resposta às variāveis dependentes, e não de forma indireta, através dos verdadeiros passos de causa, efeito e interações. Embora al gum grau de racionalidade possa ser empregado nesses modelos, a equação de regressão $\vec{e}$, antes, o somatörio das respostas observadas de uma variävel a duas outras ou mais, do que a expressão de um comportamento fundamental (ROYLE e BUTT, 1979). Neste tipo de cälculo sö há necessidade de que a variävel dependente tenha uma distribuição normal, sem que isto signifique o estabelecimento de relações de causa e efeito (BUTT e ROYLE, 1974). 
A interpretação das equações de regressão múltipla é limitada por diversas razões. Entre elas pode-se citar que alguns parâmetros chaves podem não estar incluí dos entre as variáveis escolhidas para compor a equação. De pois, a equação pode ter pouca precisão para previsões quan do os valores das variáveis independentes ficarem fora dos valores usados para o cálculo da equação. Além disto, podem ocorrer intercorrelações mascaradas entre variáveis quando se dá importância a uma variável que na reàlidade é deșpresível, porẻm altamente correlacionada com uma variável chave. Finalmente, reforçando, tem-se que não se pode estabele cer relações de causa e efeito entre as variáveis (BUTT e ROYLE, 1974).

No entanto, como todos os modelos são simplificações da realidade, o grau de simplificação inerente das regressões pode ser aceitāvel desde que satisfaça os ob jetivos do pesquisador. Assim, tem-se que o uso de regressão múltipla pode ter dois objetivos básicos. 0 método pode ser usado analiticamente para pesquisar e medir relações en tre variáveis, com a finalidade de avaliá-las em termos quan titativos e identificar os fatores chaves do sistema. Alter nat ivamente, interpretações e análise podem ter menor interesse do que a previsão de eventos futuros para melhorar o nivel de controle das doenças ou para prever perdas na produção (ROYLE e BUTT, 1979). 
Em ambos os casos pode-se encontrar diversos trabalhos publicados cujos autores empregam regressões, com maior ou menor grau de sofisticação, conforme se pode ver na revisão de KRANZ (1974) que listou 5 publicações relativas a estimativas de esporulação, outros 5 tratando de infeç̧ão, incubação e período latente, 17 sobre progresso de epidemias e 7 sobre perdas na produção.

os modelos preditivos tiveram sua evolução a partir dos anos 30 em função das correlações estabeleci das entre doença e fatores do ambiente. Esses modelos eram baseados na quantificação indireta do inóculo inicial, normal mente empregando dados macrometereológicos e o uso de re gressões l ineares como o modelo descrito por COAKLEY et alii, 1982 para o sistema Puccinia striiformis - trigo. outros mo delos preditivos são fundamentados na quantificação direta do inōculo inicial e na eficácia desse mesmo inóculo. Há, a inda, os modelos baseados no inóculo secundário e cujos de talhes podem ser encontrados na revisão de FRY (1982).

Os modelos conceituais, "podem ser concebidos como um conjunto lógico de conhecimento das interrela ções entre patógenos, hospedeiros e ambiente, conhecimento este obtido da literatura, de ensaios de laboratório e de campo, com a finalidade de se elaborar cálculos do curso de epidemias. Estes modelos podem ser considerados como o centro da epidemiologia, pois se constituem numa forma ordena- 
da de reunir os conhecimentos básicos dos componentes das epidemias para uma compreensão global da mesma (WAGGONER, 1974).

Os modelos conceituais estão baseados na nălise de sistemas e normalmente empregam computadores. Anā lise de sistemas è uma estratëgia de pesquisa para resolver problemas complexos, buscando a estrutura e o funcionamento de sistemas biolögicos. Consequentemente, ela é multidisciplinar incorporando tëcnicas e conceitos de diversas äreas da ciência e envolvendo mais análise matemática do que qual quer outro ramo da epidemiologia (KRANZ e HAU, 1980).

Em termos de abordagem de sistemas uma ep $\mathbf{i}$ demia pode ser descrita como sendo composta por diversas fá ses, tal qual mostra a Figura 1. Essas fases representam etapas pelas quais o patógeno passa durante a evolucão da epidemia.

Pode-se chamar cada uma delas de variáveis epidemiológicas e que são unidas respeitando-se os significados biológicos existentes entre elas. Podem ser representadas por meio de uma série de atributos, chamados de compo nentes do sistema epidemiológico. Como o resultado parcial obtido em cada fase serve de dado básico para a fase seguin te, taxas estão envolvidas, formando-se uma cadeia epidemio lógica. Essas taxas são influenciadas por fatores externos 
ou variāveis externas, compreendidas no ambiente. Assim, uma variāvel externa pode diminuir o efeito de uma determinada taxa e ter ação conträria em outra. Esta é a maior diferença entre modelos conceituais e os descritivos pois, nes tes, tal efeito não é possível de ser simulado (ZADOKS.1971; KRANZ, 1979).

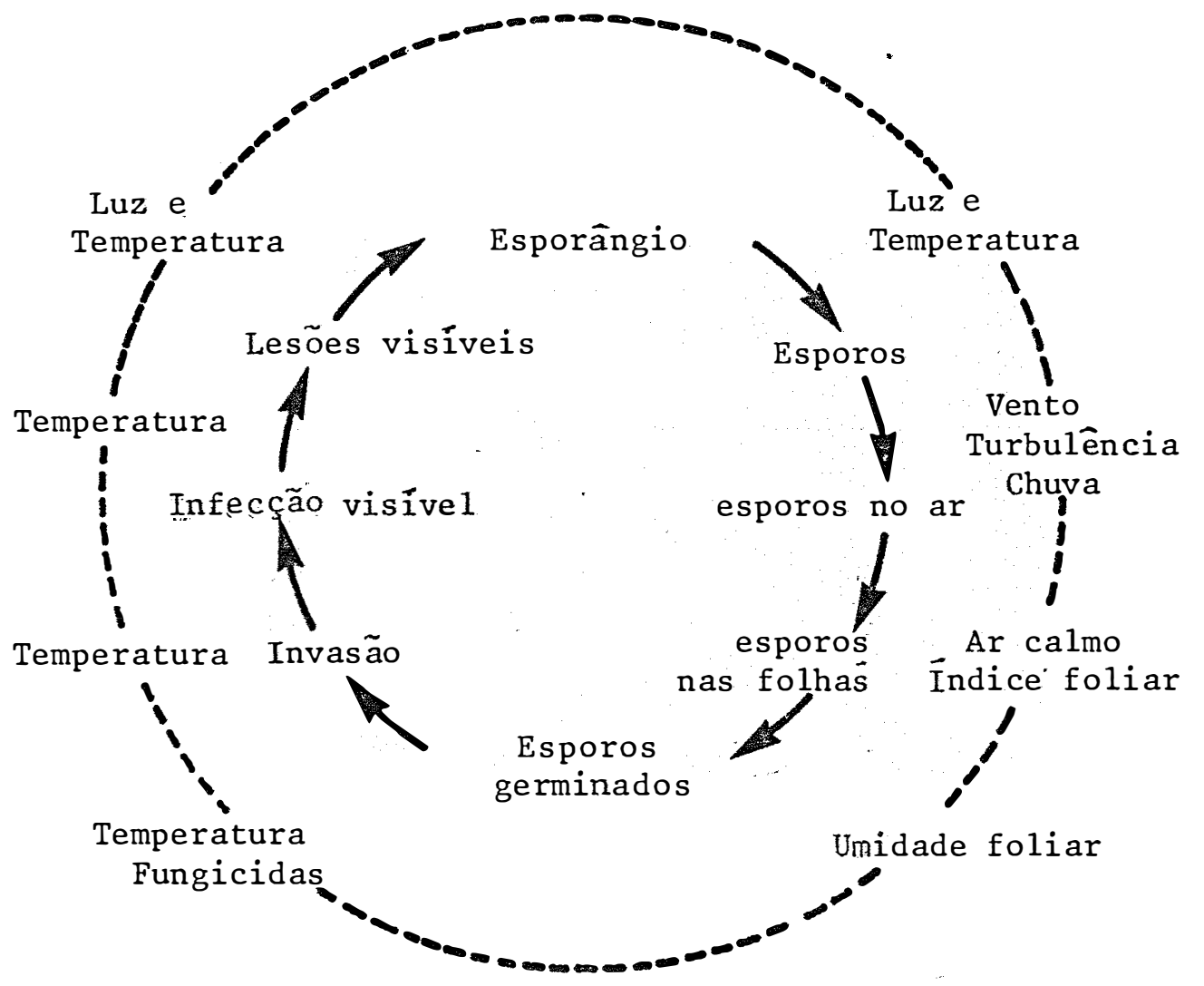

Figura 1. Diagrama esquemático representando patógeno foliar. A linha cheia inclui as principais variáveis epidemiológicas (sistema epidêmico). Os fatores ligados pela li nha tracejada indicam os fatores ambientais que atuam nas taxas de mudança das variáveis epidemiolögicas (SHRUM, 1978). 
os modelos conceituais mais difundidos são os da chamada família EPIdem (WAgGONer e HORSFALL, 1969)que incluem, entre outros, EPIMAY (WAGGONER et alii, 1972) EPISIM (ZADOKS e RIJSDIJK, 1972), EPIVEN (KRANZ et alii, 1973), EPICORN (MASSIE, 1973), EPIDEMIC (SHRUM, 1975), EPIGRAM (AUST et alii, 1983) e EPIPRE. (RABBINGE e RIJSDIJK, 1983.

Muitos modelos conceituais existentes são pouco mais do que exercícios para se ganhar experiência com as técnicas pois, quando os dados para servirem de base aos modelos não eram disponíveis, determinadas premissas teóricas tiveram que ser assumidas. Esta prática é necessária mas, deve-se enfatizar que, uma vez escolhido um determinado tipo de modelo, sua elaboração deve se basear, tanto quanto possível, em dados reais. E evidente que os modelos devem ser tão simples quanto possivel e o aumento de complexidade deve ser avaliado em termos de precisão acrescentada, conteūdo da informação fornecida, facilidade de uso e otimização dos custos de elaboração (ḰRANZ e ROYLE, 1978).

$$
\text { No entanto, segundo KRANZ (1974), quanto }
$$

mais se aprofunda no sistema epidemia os modelos adotados devem ser mais bem estruturados, particularmente em termos de anâlise de sistemas. Apesar disto, deve-se desenvolver estudos a partir de modelos simples e muitas vezes abstratos antes de que se possa modificá-los e complicá-los. 
Conclusões epidemiológicas puderam ser obtidas a partir da simulação de doenças de juros compostos com o emprego de um modelo simplificado da cadeia de infecção. Este modelo utiliza como dados de entrada no sistema o período infeccioso, latente, a quantidade de tecido sadio disponível e o nümero de esporos efetivos produzidos por unidade de tempo (ZADOKS, 1971).

Considera-se, neste caso, constante a produção de esporos efetivos durante o período infeccioso. Tal não corresponde ao que se tem observado em muitos sistemas. A produção de esporos em Puccinia hordei descreve uma curva bastante regular, assimétrica à direita, com um pico máximo abso luto no quarto dia,permanecendo do 129 ao 289 num nível inalterado e baixo (TENG e CLOSE, 1978). Produção irregular, com di versos picos durante o período infeccioso foi relatado em Phakopsora pachyrhizi, Uromyces phaseoli e Puccinia psidii (MELGHING et alii, 1979; YARWOOD, 1961; IMHOFF et alii,1982; CASTRO, 1983, FEGIES et alii, 1984, MENDES, 1985).

Estes fatos sugerem a existência de um modelo de produção de esporos para as ferrugens tropicais e outro para as temperadas, o que poderia ser incorporado na simulação de doenças de juros compostos (MENDES et alii, 1984). 
2.2. Parâmetros monocíclicos

Epidemias são processos biológicos complexos usualmente considerados como resultado de sub-processos, facilmente identificados, chamados ciclos de infecção. Assim, as doenças de juros compostos ou policíclicas nada mais são do que o resultado de uma sërie de ciclos de infecções que ocorrem num intervalo de tempo correspondente ao ciclo de determinada cultura (PARLEVLIET, 1979; ZADOKS e SCHEIN, 1979).

Parâmetros são valores ou atributos que ca racterizam processos e/ou estados de uma epidemia (KRANZ, 1981). Desta forma o processo monocíclico de uma epidemia diz respeito à ação de parâmetros que têm como intervalo de tempo um ciclo de infecção (ZADOKZ e SCHEIN, 1979). São eles frequência de infecção, período de incubação e latente, pro dução de esporos, período infeccioso, tamanho ou tipo de le são (PARLEVLIET, 1979). o entendimento básico da epidemiolo gia de determinado sistema patỏgeno-hospedeiro e a elaboração de modelos de simulação de doenças policíclicas requerem o conhecimento desses parâmetros uma vez que os mesmos determinam o valor da velocidade de crescimento da doença no tempo. o estudo dos parâmetros monocíclicos é feito com o emprego de condições controlados do ambiente (VAN DER PLANK, 1963; 1968; PARLEVLIET, 1979; KRANZ. 1981; IMHOFF et alii, $1982)$. 
Período latente è o intervalo de tempo entre a inoculação e a produção de esporos. Normalmente pode estar bastante correlacionada com o período de incubação que é o intervalo entre a inoculação e o aparecimento dos primeiros sintomas. Diferenças entre os dois parâmetros têm si do observadas assumindo-se que sejam reflexo de diferentes taxas de crescimento do patögeno no hospedeiro ( PARLEVLIET, $1975,1979)$.

A determinação do nümero de horas do perío do latente tem sido feito com o emprego de contagens cumula tivas apös a constatação dos primeiros uredossoros com espo ros até que novos uredossoros maduros não mais aparecem. Con sidera-se como período de latência o intervalo de tempo entre a inoculação e o aparecimento de $50 \%$ dos uredossoros produtivos, determinados graficamente (MEHTA e IGARASHI, 1979; SHANER et alii, 1978; TORMELIN et alii, 1983; MENTEN, $1980)$.

$H \vec{a}$ controversias com relação a essa metodo logia uma vez que pela definição dada por VAN DER PLANK (1963) dever-se-ia considerar como período latente a erupção do primeiro uredossoro o que diminuiria o valor do período latente e aumentaría o do período infeccioso (TENG e CLOSE, $1978)$ 
Ensaios realizados com o sistema Puccinia recondita f.s.p. tritici e trigo mostraram que os cultivares testados não diferiam em ordem, independentemente do critério adotado para estabelecer o valor do período latente, ten do-se inclusive considerado um terceiro critērio de contar o período latente até o aparecimento do ültimo uredossoro (TORMELIN et alii, 1983). Desta forma tem prevalecido na li teratura o emprego de determinação gräfica do período laten te como tempo entre a inoculação e o aparecimento de $50 \%$ das lesões maduras.

Período infeccioso è definido como o tempo durante o qual a lesão mantēm-se esporulando (PARLEVILIET, 1979). A determinação desse parâmetro estä relacionada com a produção de esporos e normalmente apresenta uma correlação negativa com a frequência de infecção. Existe um limite biológico a partir do qual altas frequências levam à morte prematura de folhas, reduzindo, desta forma, o período infeccioso. A ocorrência de baixas densidades de lesão permite, no caso das ferrugens, o aparecimento de uredossoros sa télites, o que prolonga o período infeccioso. Desta forma, antes de se iniciar ensaios visando determinar o período in feccioso de determinado patögeno é necessärio estabelecer uma concentração de inóculo compatível com a quantidade de doença encontrada em condições naturais de infecção para não alterar o padrão de resistência da planta e, consequen- 
temente, os valores dos parâmetros monocíclicos (YARWOOD, 1960; ARLEN et alii, 1964; MEHTA e ZADOKS, 1970; PARLEVLIET, 1979; IMHOFF et alii, 1982).

o período infeccioso tende a sofrer altera ções em seus valores em função do efeito indireto que fatores do ambiente, tais como temperatura, umidade, produzem no período latente. Uma vez iniciada a produção de esporos esta tende a se manter até que ocorra a morte da folha ou da lesão (PARLEVliet, 1979; STANLey et alii, 1979; MeHTA e ZADOKS, 1970; IMHOFF et alii, 1982).

Alterações significativas, de zero a trinta dias, na duração do período infeccioso foram obtidas ino culando-se diversas raças de Helminthosporium sativum em fo lhas bandeiras de trigo (MEHTA, 1981). Resultados semelhantes ocorreram no sistema Puccinia recondita f.s.p. tritici e trigo mantendo-se constante a raça do patógeno e variando -se os cultivares de trigo portadores de diferentes gens de resistência (TORMELIN et alii, 1983), sugerindo que estudos semelhantes devam ser conduzidos em outros sistemas antes de se estabelecer um período infeccioso padrão.

Finalmente, o estádio fenolögico do hospedeiro ao ser inoculado tambëm leva a diferentes valores de período infeccioso (TORMELIN et alii, 1983). 
A produção de esporos tem sido expressa em quantidade de esporos por unidade de ärea foliar, por lesão ou por unidade de superfície esporulante. Essas unidades de äreas podem ser medidas em unidades de tempo ou em função do período infeccioso como um todo (PARLEVLIET, 1979).

A determinação da produção de esporos está inversamente correlacionada com a frequência de infecção. Baixas concentrações tendem a levar a um aumento na produção de esporos, qualquer que seja a unidade de tempo empregada. Assim, a frequência de infecção deve ser o mais uniforme possível para que se possa estabelecer valores comparäveis de produção de esporos (PARLEVLIET, 1979; YARWOOD, 1961; IMHOFF et a Zii, 1982).

A idade das folhas tambëm condiciona a pro dução de esporos, tendo estudos conduzidos ... no... sistema Uromyces phaseoli var typica e feijão indicado que as foIhas jovens, inoculadas aos 11 dias apōs emergência, produzem mais esporos por dia ou mesmo levando em consideração todo o período infeccioso, do que aquelas inoculacões aos 25 dias (IMHOFF et ali $i$, 1982). Diferenças no sentido inver so foram encontradas no sistema Puccinia recondita f.s.p. tritici e trigo a partir de inoculações nos estädios de plântula e florescimento (TORMELING et a zií, 1983). 
o sistema Uromyces phaseoli var typica tem apresentado dados discrepantes com relação ao efeito da umi dade relativa e a produção de esporos. Estudos mais recen tes têm sugerido que a umidade é de pouca importância na ta xa de esporulação, necessitandomse, porëm, de mais ensaios sobre assunto (IMHOFF et alii, 1982).

Já a influência da temperatura estä bastan te firmada na literatura de forma que estudos visando a ela boração de modelos de simulação que incluam a produção de esporos como parâmetro, devem ser realizados sob diversas temperaturas para que se possa obter uma curva característ ca da variedade e do isolado (WAGGONER, 1974; TORMELIN et a $2 i i, 1983$; TENG e CLOSE, 1976; IMHOFF et alii, 1982),

A frequência de infeção è medida pelo nümero de lesões produzidas quando se inocula uma concentração conhecida de esporos. Ela dä uma idëia não sō da resis tência à penetração como tambèm da resistência à coloniza ção (PARLEVLIET, 1979).

o termo receptividade tem sido utilizado por alguns autores sob a justificativa de que o conceito es tá mais relacionado com características do hospedeiro. Porëm, o papel de baixa receptividade como um componente de resistência horizontal é pouco entendido principalmente for que há dificuldades metodológicas em sua avaliação. Trata se de um parâmetro ao qual está associado altos desvios pa- 
drões uma vez que alterações ocorrem na fisiologia das folhas conforme envelhecem, modificando os padrões de recept vidade. Tais modificações tendem a ocorrer em unidades de tempo menores do que a unidade experimental. Por outro lado o tipo de folha também apresenta padrões de receptividade diferentes na medida em que facilitam ou dificultam a deposição de esporos (GROTH e URS, 1982; PARLEVLIET e KUIPPER, 1977 ; RUSSEL, 1975).

A frequência de infeção ou receptividade é um dos parâmetros que dão uma indicação aproximada do valor da eficiência (E). Quando multiplica-se a eficiência pe् lo número de esporos produzidos obtém-se a taxa bäsica de infeção corrigida (Rc) (VAN DER PLANK, 1963; PARLEVLIET, 1979). Devido à dificuldade metodológica na obtenção do parâmetro frequência de infecção, pode-se calcular o valor e $\underline{s}$ timado de Rc, para doenças de juros compostos, a partir dos valores do período infeccioso, latente e da taxa de infec. ção aparente $\left(r_{1}\right)$ (VAN DER PLANK, 1963 pag. 101). Outra opção consiste no emprego de plantias armadilhas que, coloca das periodicamente na cultura, podem fornecer informações sobre o valor Rc real, naquelas condições experimentais. Os esporos germinados são visualizados em microscópio ötico com o emprego de uma resina especial (AUST et alii, 1983). 


\section{MATERIAL E MÉTODOS}

3.1. Elaboração de modelo de simulação

$$
3 \cdot 1.1 \text {. Diagrama }
$$

A primeira etapa na elaboração dó modelo de simulação constou em estabelecer os limites do sistema (JEFFERS, 1978; KRANZ e HAU, 1980). Desta forma considerouse somente doenças que seguiam uma dinâmica de juros compos tos conforme a equação diferencial proposta por VAN DER PLANK $(1963):$ 
$\frac{d x_{t}}{d t}=R_{c}\left(x_{t-p}-x_{t-i-p}\right)\left(1-x_{t}\right)$, onde,

$X=$ proporção de tecido doente;

$\mathrm{t}=\mathrm{tempo}$

$p=$ período latente;

$i=$ período infeccioso e;

$R_{c}=$ fator de proporcionalidade (taxa básića de infecção corrigida).

A etapa seguinte foi a conversão dessa equação num modelo diagramático (KRANz e HAU, 1980), conforme Figura 2, permitindo a visualização do funcionamento glo bal do sistema.

o diagrama representa o processo de geração de tecido doente $x_{t}$. De acordo com a equação proposta, existe uma quantidade conhecida de tecido sadio que vai diminuindo com o tempo conforme à epidemia avança. Este avanço ocorre a partir da quantidade de tecido doente infeccioso $\left(x_{t-p}-x_{t-i-p}\right)$ que no tempo 1-e representado por uma pústula infecciosa $X I(1)$ multiplicada pela quantidade de es poros efetivos que essa püstula produz $\left(R_{c}\right)$. No entanto a quantidade de novo tecido doente produzido não depende ex- 
clusivamente desse produto, devendo ser multiplicado por um fator de correção $\left(1-x_{t}\right)$ que representa o efeito da diminuição de tecido sadio por já existir um espaço, ocupado (XI(1)). No diagrama esse efeito é simbolizado pelo registro abaixo do depósito de tecido sadio.

O período latente, no diagrama, é represen tado pela figura em cujo interior se encontra o tecido doen te em estado latente (XL (M)) gerado a cada intervalo de tempo (M). O total de divisões internas da figura representa o valor, em tempo, do período latente.

Vencido este "atraso" na epidemia o tecido latente se torna infeccioso $(X I(M))$ e passa a ser representado na figura relativa ao tecido infeccioso. A cada unidade de tempo o tecido infeccioso ( $X I(M)$ ) produz uma quantida de de esporos respresentados pelos dutos com uma torneira: A maior parte desses esporos são.eliminados durante o processo de disseminação, inoculação e germinação. Este fato está repre sentado pela saída de esporos perdidos. Os esporos efetivos são conduzidos pelo duto com a 'grafia Rc ate o encontro com o tecido sadio, quando produzem novas infecções (XL(M)). 


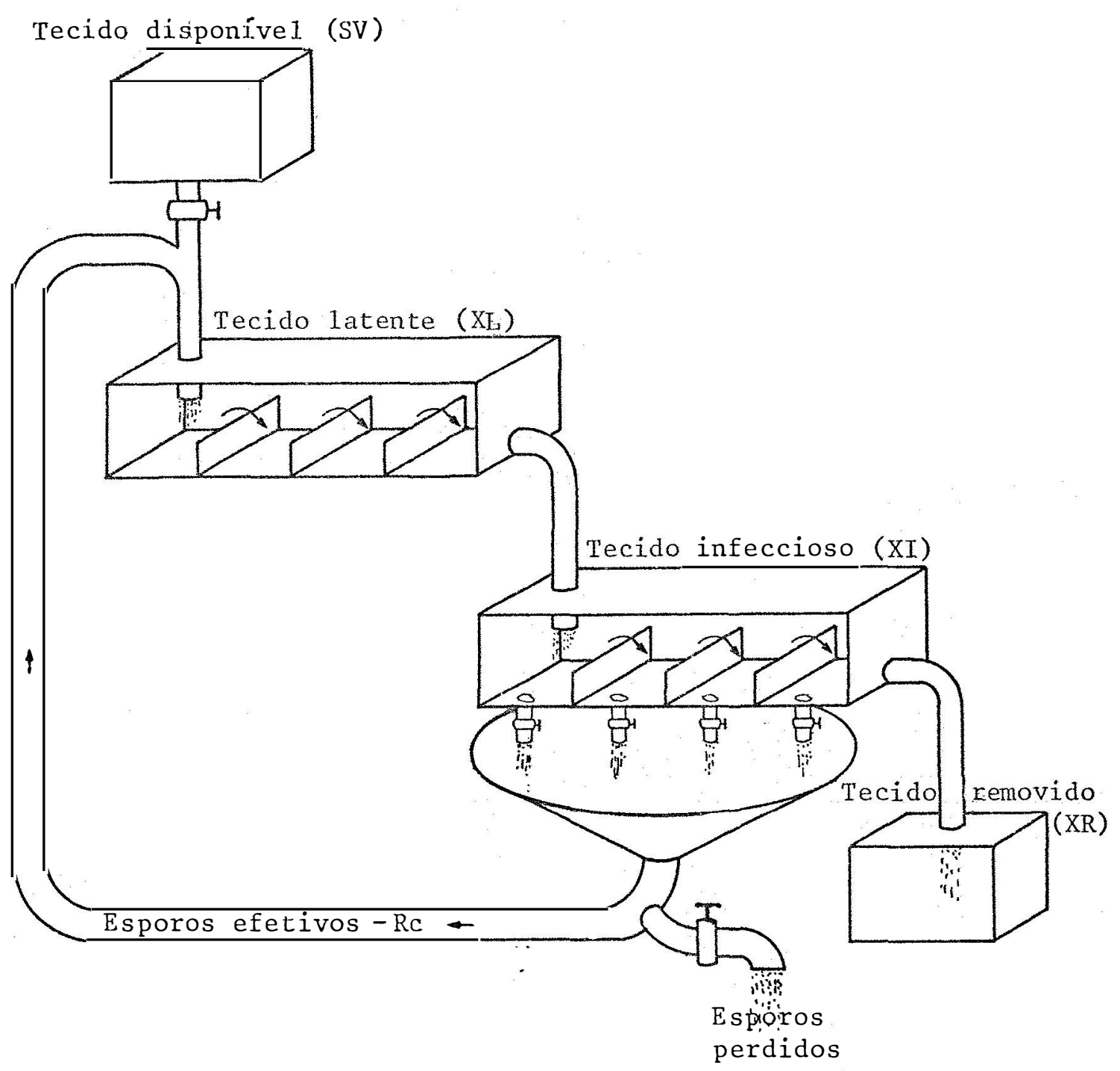

Figura 2. Representação física da dinâmica de uma epidemia basea da na equação diferencial: $\frac{\mathrm{dx}_{t}}{\mathrm{~d}_{t}}=\mathrm{R}_{c}\left(\mathrm{x}_{t-\mathrm{p}}-\mathrm{x}_{t-\mathrm{p}-\mathrm{i}}\right)\left(1-\mathrm{x}_{t}\right)$, onde, $x_{t}=$ tecido doente $; t=$ tempo numa unidade qualquer; $\mathrm{p}=$ período latente; $i$ = período infeccioso $\mathrm{e}$ $\mathrm{R}_{\mathrm{c}}=$ taxa bāsica de infecção corrigida. 
Terminado o período infeccioso o tecido é acumulado numa figura para tecido removido que quando com pleta representa o fim da epidemia.

A quantidade total de tecido doente $\left(x_{t}\right)$ é obtida pela soma da quantidade de tecido em estado latente $(X L)$, infeccioso $(X I)$ e removido $(X R)$ :

\subsubsection{Programa}

A partir do diagrama passou-se à elabora ção de um fluxograma, etapa que antecede a transcrição do modelo em linguagem de computador.

Visando facilitar sua descrição, o fluxograma, que é reproduzido na figura 3 , foi subdividido em 6 etapas, de "A" a "G", devidamente assinaladas.

Há quatro etapas básicas (A, C, E e G) que estão diretamente ligadas à dināmica descrita no diagrama. 0 conjunto de rotinas agrupadas no fluxograma pelas letras B, D, F, fazem parte do programa para solucionar duas situacões espe cíficas, quais sejam, quando o tempo (M) e o período infeccioso (FE) forem iguais a unidade.

Na etapa "A" estabelece-se a quantidade de tecido disponivel no tempo $M(X V(M))$, por meio da expressão: 


$$
X V(M)=S V-X T(M-1) \text {, onde }
$$

SV e a quantidade total de tecido disponível no início da simulação;

XT $(M-1)$ é a quantidade total de tecido doente no tempo ime diatamente anterior.

Em seguida há o cálculo da variável de con trole de período latente (J) com a expressão:

$$
J=M-L P \text {, onde. }
$$

LP é o valor do período latente do sistema em estudo.

Finalmente è obtido o fator de correção(CO) no tempo $M$, por meio da expressão:

$$
C O(M)=X V(M) / S V
$$

No programa (Apèndice 1) essas rotinas receberam os nümeros 120 e 125 .

A etapa B tem início verificando-se se a variável $M$ é igual à unidade. Em caso afirmativo o programa calcula.a quantidade de tecido latente ( $X L)$. que serä 


$$
X L(M)=M(M) C O(M) \text {, onde }
$$

MD

representa o número de esporos efetivos.

Em seguida verifica-se se operíodo infeccioso (FE) é igual à unidade. Em caso afirmativo, o tecido removido (XR) è atualizado a cada intervalo de tempo $(X R(M)=X I(1))$ e ào tecido infeccioso $(X I)$ e atribuído o va lor zero $(X I(M)=0)$. Caso o período infeccioso (FE) seja diferente da unidade não há tecido removido $(X R(M)=0)$ e ao tecido infeccioso ( $X I)$ no tempo (M) é atribuído o valor da unidade $(X I(M)=1)$. Uma vez que o período infeccioso é igual à unidade não há necessidade das etapas C, D, E e o programa è desviado para etapa F.

Caso o tempo (M) não seja igual à unidade hä necessidade de novamente se verificar se o período infec cioso (FE) é unitário. Sendo afirmativo o valor do tecido removido é atualizado $(X R(M)=X((1))$ e o programa é desvia do para a etapa $D$.

A etapa 8 consta das instruções $130,140,143$, 145 e 150 do programa em anexo (Apêndice 1).

Na etapa C procede-se à atualização dos va lores do tecido infeccioso (XI) quando o período infeccioso e o tempo forem maiores que a unidade. A rotina é repetida 
o nümero de dias relativo ao período infeccioso (FE), o que é controlado com auxílio da variável z e cujo comando, em $B A S I C, \bar{e}$

\section{FOR $Z=1$ TO FE}

No proximo passo verifica-se se o valor $z$ corresponde à unidade. Em caso afirmativo atribui-se à variāvel auxiliar (PO) o valor do tecido infeccioso (XI), ambas indexadas por Z. A variável po tem a finalidade de arma zenar os valores de $X I$ que serão atualizados. No passo seguinte verifica-se se o período latente já terminou. Caso a variavel J seja menor ou igual a zero não há a passagem de tecido latente a infeccioso, o que é obtido com a expressão

$$
X I(Z)=0
$$

Ao contrário, se o programa rodou um nümero de vezes maior que o valor do período latente, atribui-se à variavel XI(Z) o valor do tecido latente (XL) indexado por J.

A rotina prossegue com a atualização do va lor de $Z$ que passa a ser acrescido de uma unidade. Nesta etapa o programa verifica se $Z$ é igual ao valor do período infeccioso. Em caso negativo, o valor de $X I(Z)$ é conservado 
na variável auxiliar $P O(z)$ e procede-se à atualização da quantidade de tecido infeccioso através da expressão

$$
X I(Z)=P O(Z-1)
$$

Se o valor de $z$ corresponder ao valor do período infeccioso procede-se à atualização da quantidade de tecido removido $(X R(M))$, atribuindo-se o valor de $X I(Z)$. No pröximo passo há a atualização do valor de $X I(Z)$ com a expressão

$$
X_{1}(z)=P O(z-1)
$$

No programa (Apêndice 1) essa etapa está agrupada entre as 1 inhas de número 165 a 200 , inclusive.

O programa só passa pela etapa d quando o período infeccioso for igual à unidade. Neste caso, após a atualização do valor do tecido removido (XR), ainda na etapa $B$, verifica-se se o programa jä rodou um nümero de vezes menor ou igual ao valor do período latente. Caso afirmativo não haverá tecido latente se transformando em tecido infeccioso, o que é obtido com a expressão

$$
x I(1)=0
$$

Sendo negativo atualizamse o valor do tecido infeccioso atribuindo-se a este o valor de XL(J). 
Essa etapa corresponde às instruções de nư meros 210 e 215 do programa em anexo (Apêndice 1).

Na etapa E calcula-se a quantidade de teci do doente. Para tanto, emprega-se um contador com a variavel $Z$ o que, em BASIC, é representado por

FOR $Z=1$ TOFE

A variável PI é um acumulador da quantidade de tecido infec cioso através da expressão

$$
P I=X I(Z)+P I
$$

A quantidade total de novo tecido doente é obtido multiplicando-se o tecido infeccioso $X I(Z)$ fela correspondente quan tidade de esporos efetivos (MD (.Z)), acrescida do valor de tecido doente anteriormente gerado (VI). Esta rotina é que permite o estudo dos modelos de produção de esporos na medi da em que a cada etapa $Z$ do peŕfodo infeccioso pode-se atri buir um índice MD de esporos efetivos produzidos. Ao término dessa etapa atualiza-se o valor da variavel Sl, que representa o total de tecido infeccioso no tempo $M$ e obtëm-se o total de tecido latente (XL) no tempo (M), corrigindo -se a quantidade de tecido doente (VI) pelo fator de correção ( $C O(M))$ : As variaveis VI e PI são, então, zeradas. 
No programa, a etapa E corresponde às 1 i nhas entre os nümeros 220 e 235, inclusive (Apêndice 1).

$$
\text { A etapa } F \text { estabelece um contador para à }
$$
obtenção da quantidade de tecido latente (SP(M)). Caso o período latente (LP) seja maior ou igual à unidade de tempo M, a variävel J será menor ou igual a um e ao contador simples mente se acrescentarä o valor da quantidade de tecido laten te gerado no tempo $(M)$, através da expressão

$$
S P(M)=S P(M+1)+X L(M)
$$

Se a variavel J tiver valor positivo, maior que 1 , significa que hă tecido latente que se transformou em infeccioso $(X L(J))$ e portanto a expressão passa a ser

$$
S P(M)=S P(M-1)+X L(J)+X L(M)
$$

Esta etapa- $\vec{e}$ finalizada com uma pequena rotina para garantir que o valor da quantidade de tecido latente ( $S P(M)$ ) seja sempre, pelo ao menos, igual a zero.

No programa, a etapa $F$ consta das instruções entre os nümeros 240 a 250 (Apêndice 1).

A- Ül tima etapa rapresentada no fluxograma consta de uma rotina de atualização dos valores da quantida de total de tecido doente $(X T(M))$. 
No primeiro intervalo de tempo o valor de XT(M) é obtido pela soma dos valores de tecido latente $(X L(M))$, infeccioso $(X \mid(M))$ e removido $(X R(M))$. A partir do segundo momento a quantidade total de tecido doente (XT(M)) será igual à anterior acrescida do tecido latente (XL(M)).

No programa essa etapa corresponde às 1 i nhas entre os nümeros 255 a 265 , inclusive, (Apêndice 1). Hā, ainda, rotinas que comandam o retorno ao início do programa, associadas às rotinas de impressão de dados. Neste caso não há maior interesse em descreve-las pois pouco acrescentam à compreensão do sistema como um todo e serão peculiares ao equipamento em que se estiver traballhando.

A fim de facilitar a leitura da Figura 3 , apresentamos abaixo um sumärio das variaveis ali. encontradas:

$\mathrm{CO}=$ Fator de correção;

$F E=$ Período infeccioso;

$J=$ Variävel de controle de período latente;

$L P=$ Periodo latente;

$M=$ Tempo;

$M D=$ Número de esporos efetivos;

$P I=$ Acumulador da quantidade de tecido infeccioso;

SI = Tecido infeccioso parcial;

$S P=$ Tecido latente parcial;

$S V=$ Quantidade inicial de tecido disponível;

$V I=$ Acumulador da quantidade de tecido doente;

$X I=$ Quantidade total de tecido infeccioso;

$X L=$ Quantidade total de tecido latente;

$X R=$ Quantidade total de tecido removido;

$X T=$ Quantidade total de tecido c'oente;

$X V=$ Quantidade total de tecido disponivel. 


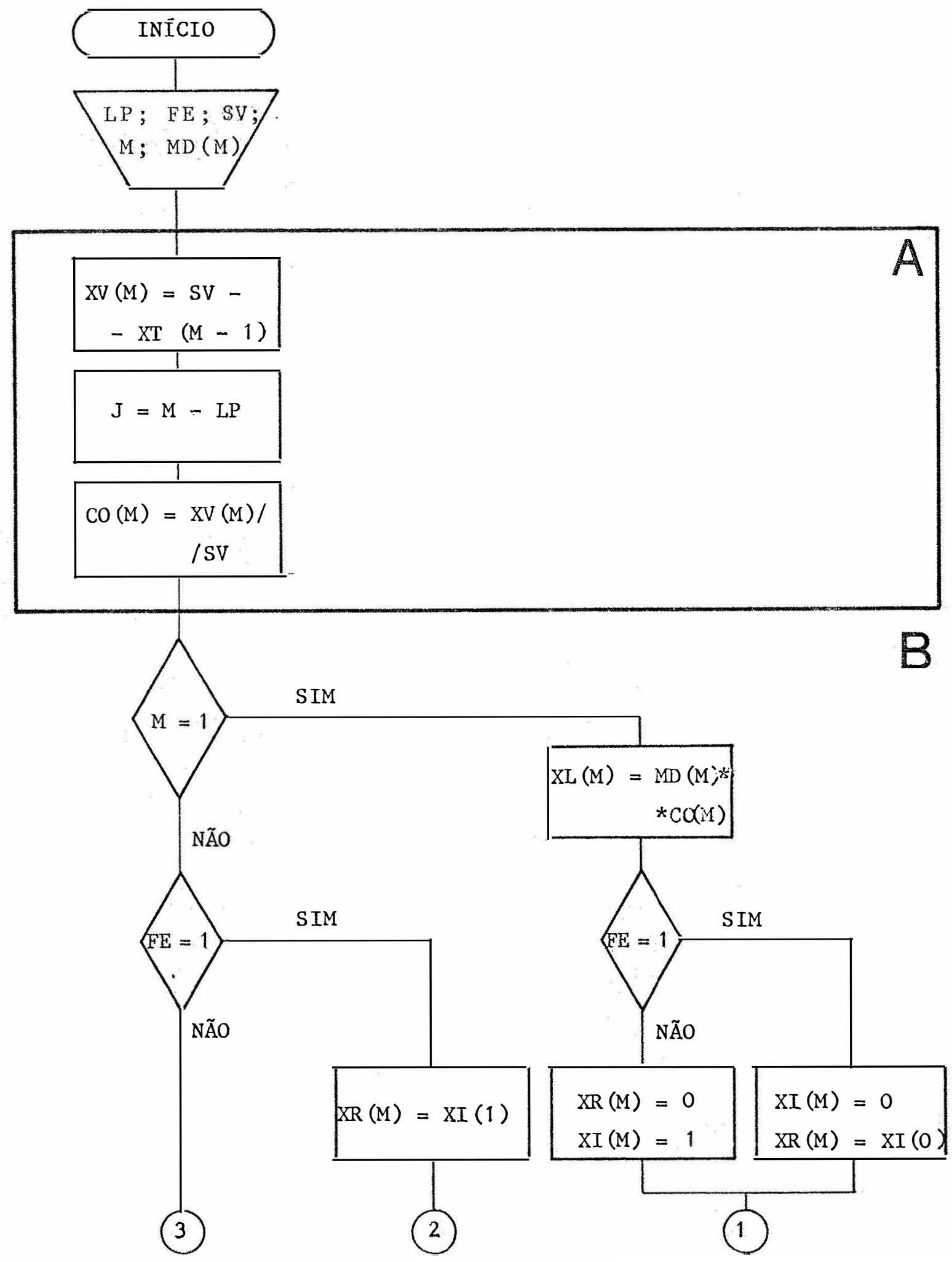

Figura 3 - Fluxograma do modelo de simulação de doenças elaborado a partir da equação diferencial e do modelo diagramático indicados na Figura 2. Continua nas päginas seguintes. 

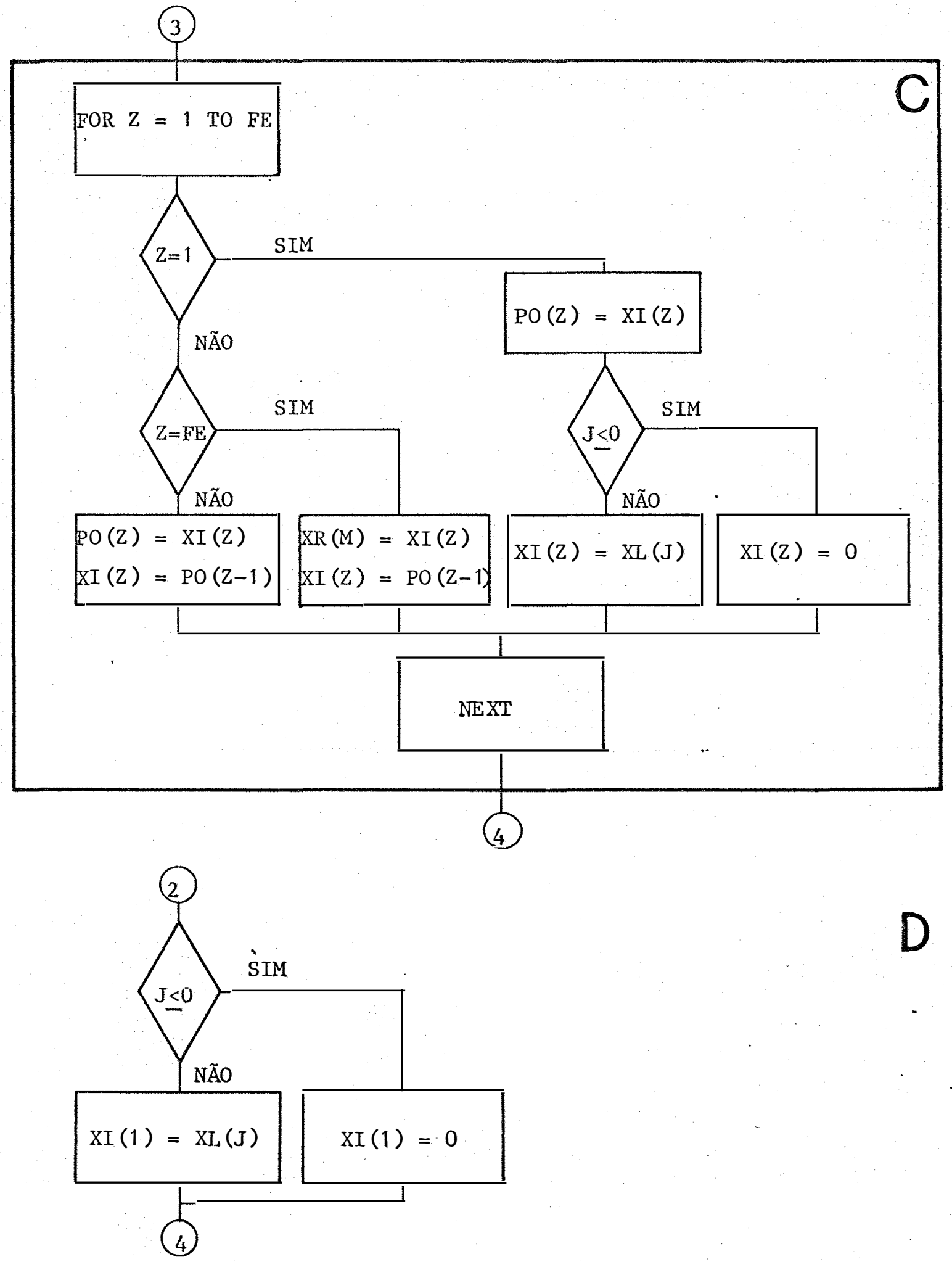

D

Figura 3 - Continuaçào do fluxograma do modelo de similação de doenças elaborado a partir da equação diferencial e do modelo diagramático indicado na figura 2. Continua na pägina seguinte. 


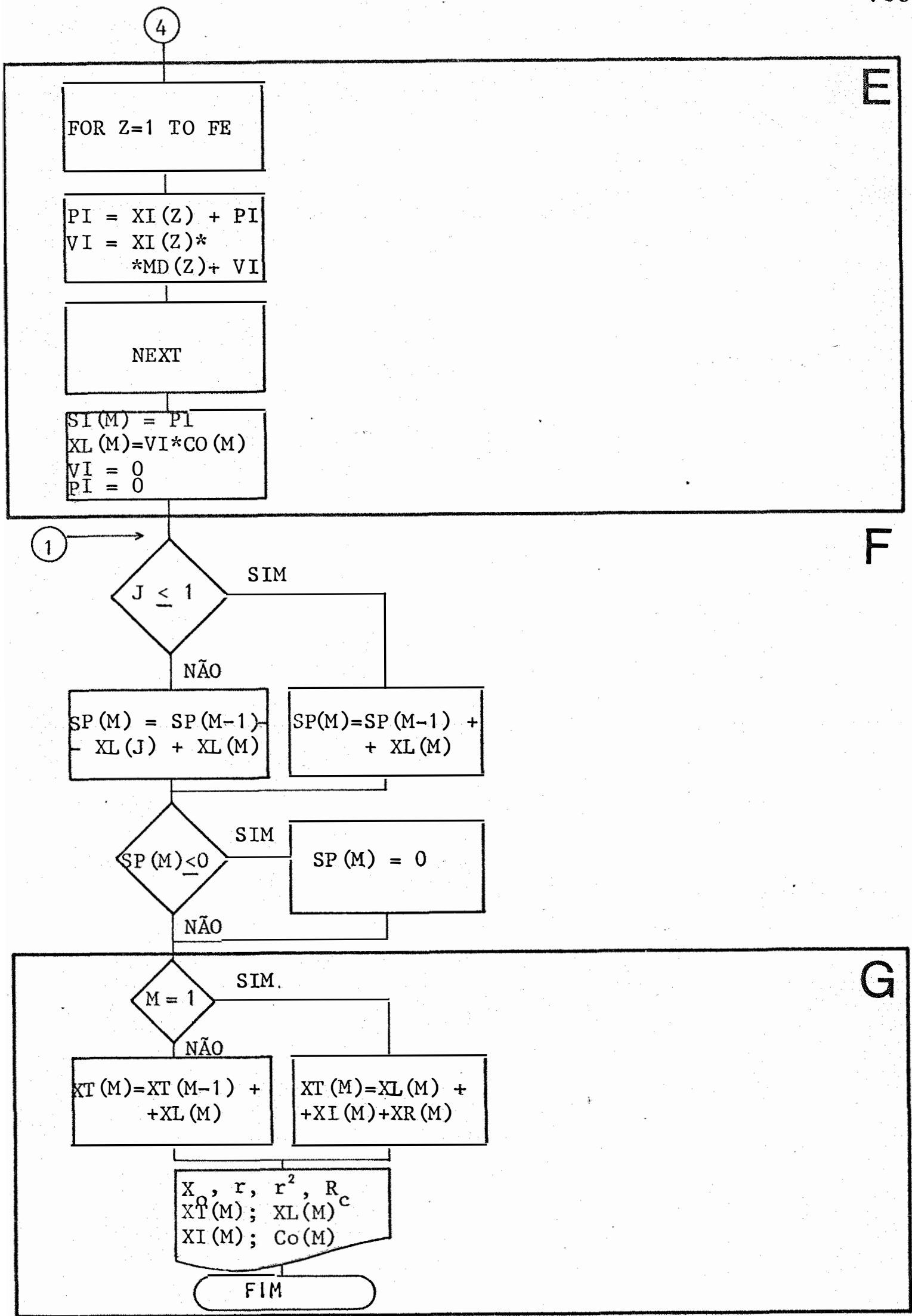

Figura 3 - Continuação do fluxograma do modelo de similação de doenças elaborado a partir da equação diferencial e do modelo día gramätico indicados na figura 2 . 
3.2. Verificação do modelo

A verificação se o comportamento geral dos valores gerados representam razoavelmente bem o sistema em estudo foi realizada em duas etapas, considerando-se o tempo, em ambos os casos, variando de 0 a 60 com incremento de 1 dia. A primeira etapa teve por objetivo observar se o modelo estava gerando dados que uma vez colocados em forma gräfica decimal se assemelhavam às curvas sigmöides esperadas num modelo logístico. os dados $\underline{u}$ ti lizados nessa fase estão sumarizados na tabela 1 .

Tabela 1 - Valores de parâmetros epidemiológicos utilizados para verificação do modelo com relação à sua capacidade de gerar dados que uma vez postos em forma grä́fica produzam curvas sigmöides.

\begin{tabular}{cccc}
\hline Verificação & $\begin{array}{c}\text { Perído } \\
\text { Latente } \\
\text { (dias) }\end{array}$ & $\begin{array}{c}\text { Periodo } \\
\text { Infeccioso } \\
\text { (dias) }\end{array}$ & $\begin{array}{c}\text { Taxa aparente de } \\
\text { infecção corrigida } \\
\text { (unidade/dia) }\end{array}$ \\
\hline 1 & 4 & 4 & 16 \\
2 & 1 & 1 & 2 \\
\hline
\end{tabular}


A segunda etapa do processo de verificação do modelo teve por objetivo observar se os dados gerados reproduziam aqueles obtidos pela equação diferencial da qual o modelo foi elaborado. Para tanto recorreu-se a parâmetros epidemiológicos dos sistemas: Phytophthora infestans - batata (VAN DER PLANK, 1963) e Puccinia graminis - trigo(VAN DER PLANK, 1963), sumarizados na tabela 2 .

Tabela 2 - Valores de parâmetros epidemiológicos utilizadospa ra verificação do modelo com relação à sua capací dade de gerar dados semelhantes àquele obtidos pe la equação diferencial da qual o modelo foi elabo rado.

\begin{tabular}{lccc}
\hline Sistema & $\begin{array}{c}\text { Período } \\
\text { Latente } \\
\text { (dias) }\end{array}$ & $\begin{array}{c}\text { Periodo } \\
\text { Infeccioso } \\
\text { (dias) }\end{array}$ & $\begin{array}{c}\text { Taxa aparente de } \\
\text { infecção corrigida } \\
\text { (unidade/dia) }\end{array}$ \\
\hline $\begin{array}{l}\text { P. infestans } \\
\text { batata }\end{array}$ & 4 & 1 & 7 \\
$\begin{array}{l}\text { P. graminis } \\
\text { trigo }\end{array}$ & 10 & 10 & 36 \\
\hline
\end{tabular}

Os períodos latente e infeccioso utilizados são valores médios dos sistemas em questão e foram adotạ dos por VAN DER PLANK (1963) a partir de värios trabalhos ex perimentais, prōprios ou não. A taxa aparente de infeçãocor rigida foi obtida pela equação 


$$
R_{c}=r \frac{e^{(i+p) r}}{e^{i r}-1}
$$

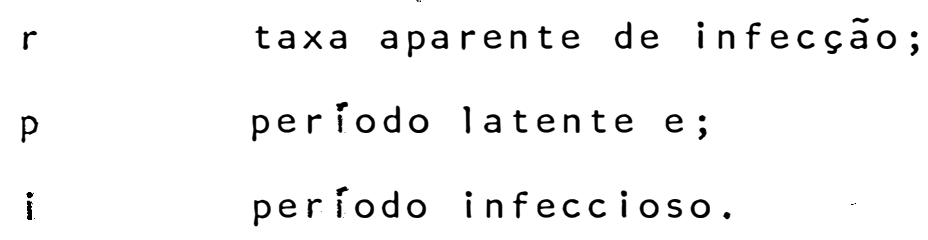

A taxa aparente de infecção $(r)$ empregada foi obtida a partir da anālise de dados de épidemias avaliadas periódicamente sob condições naturais e cujos dados foram transformados em logito $(\ln x /(1-x))$ onde $x$ índice da quantidade de doença. Posteriormente foi calculada a regressão linear dos dados transformados sendo que o coeficiente an gular representa a taxa aparente de infeccão, que para os sistemas em estudo correspondem a 0,44 unidades/dia.

3.3. Simulação do efeito de alterações no período infeccioso

O efeito simulado de alterações no período infeccioso foi obtido mantendo-se o periodo latente constante em 4 dias, assim como o valor da taxa bäsica de infecção corrigida em 16 unidades por dia e a quantidade de tecido disponível em $5.10^{13}$ unidades de ärea foliar. A variação do período infeccioso foi simulado com valores de $1 ; 2 ; 4 ; 8 ; 16$ e 25 dias (ZADOKS, 1971). 
3.4. Simulação do efeito de alterações no período latente o efeito simulado de alterações no período latente foi obtido mantendo-se o período infeccioso constante em 8 dias assim como o valor da taxa bäsica de infecção corrigida em 16 unidades por dia e a quantidade de tecido disponível em $5 \cdot 10^{13}$ unidade de àrea foliar. A variação do pe ríodo latente foi simulado com os valores de $1 ; 4 ; 8 ; 12$ e 16 dias (ZADOKS, 1971).

3.5. Simulação do efeito de alterações na quantidade de tecido disponível

o efeito simulado de alterações na quantidade de tecido disponível foi obtido mantendo-se constantes os valores do período latente ( 4 dias), do período infeccioso ( 4 dias) e da taxa básica de infecção corrigida (16 unida des por dia). A variação da quantidade de tecido disponível foi simulada com valores de $5 \times 10^{3} ; 5 \times 10^{6} ; 5 \times 10^{8}$ e $5 \times 10^{13}$ unidades de ärea foliar.

3.6. Simulação do efeito de padrões de produção de esporos efetivos

A simulação do efeito de padrões de produção de esporos efetivos foi baseada na premissa de que exis- 
te uma relação constante entre produção de esporos e a quantidade de esporos efetivos. Desta forma uma curva acompanha a outra no tempo diminuída tão somente pelo efeito da eficiência de infecção (E). Isto significa que se houvesse uma eficiência de $100 \%$ todos os esporos produzidos seriam efetivos.

Por outro lado, considerou-se que a eficiência foi constante durante todo o período infeccioso para que se pudesse isolar o eventual efeito da produção de espo$\operatorname{ros}(N)$.

o efeito dos padrões de produção de esporos foram comparados entre si sempre com a mesma quantidade total de esporos efetivos produzidos durante o período in feccioso, caso houvesse somente uma pústula infecciosa. Para tanto estabeleceram-se indices percentuais relativos a cada modelo de produção, de maneira que fornecendo-se a quantidade total de esporos efetivos relativos ao período infeccioso hä uma rotina apropriada do programa que calcula a quantidade de esporos efetivos diäria em função do indice estabeleci do.

Foram estudados quatro padrões básicos de produção de esporos efetivos estabelecidos em porcentagem. 0 padrão 1 foi baseado nas curvas: de produção de esporos acumulados apresenta dos por TENG e CLOSE (1978), relativas à Puccinia hordei, ob tidas a $20^{\circ} \mathrm{C}$. 0 padrão 2 foi obtido através de uma inversão 
grä́ica dos dados relativos ao modelo 1 , de forma que o sistema apresenta o máximo de produção no final do período infec cioso. o padrão 3 foi baseado na curva de produção de esporos de Uromyces phaseoli, apresentada por IMHOFF et alii, (1982), obtida a $21^{\circ} \mathrm{C}$, com baixa densidade de pústulas por folha. O quarto modelo, à semelhança do proposto por ZADOKS (1971), emprega uma produção de esporos constante durante to do o. período infeccioso. Para cada padrão, por sua vez, foram estabelecido dois períodos infecciosos, de $8^{\circ}$ e de 25 dias, con forme Tabelas 3 e 4 .

Tabela 3 - Indices de esporos efetivos (MV) com periodo de infeç̧ão de 8 dias.

\begin{tabular}{llll}
\hline & Padrão & Padrão 2 & $\begin{array}{l}\text { Padrão } 3 \\
\text { Tndices }\end{array}$ \\
\hline 1 & Indices & Indices & 0,11927 \\
2 & 0,44678 & 0,01204 & 0,27856 \\
3 & 0,34856 & 0,00126 & 0,06 \\
4 & 0,00482927 & 0,01338 & 0,37578 \\
5 & 0,03389 & 0,03389 & 0,07 \\
6 & 0,01338 & 0,00482 & 0,03213 \\
7 & 0,00126 & 0,34856 & 0,03213 \\
8 & 0,01204 & 0,44678 & 0,03213 \\
\hline
\end{tabular}


Tabela 4 - Indices de esporos efetivos (MV) com período de infecção de 25 dias.

\begin{tabular}{|c|c|c|c|}
\hline & Padrão 1 & Padrão 2 & Padrão 3 \\
\hline Dias & Tndices & Indices & Tndices \\
\hline 1 & 0,0241 & 0,00346 & 0,0241 \\
\hline 2 & 0,0964 & 0,00241 & 0,0964 \\
\hline 3 & 0,2651 & 0,00121 & 0,1551 \\
\hline 4 & 0,0964 & 0,00120 & 0,0664 \\
\hline 5 & 0,1687 & 0,00121 & 0,1087 \\
\hline 6 & 0,0964 & 0,00120 & 0,0964 \\
\hline 7 & 0,0723 & 0,00121 & 0,0423 \\
\hline 8 & 0,0482 & 0,00602 & 0,0482 \\
\hline 9 & 0,03615 & 0,00603 & 0,03615 \\
\hline 10 & 0,0241 & 0,00602 & 0,1341 \\
\hline 11 & 0,01205 & 0,00603 & 0,04205 \\
\hline 12 & 0,01205 & 0,00602 & 0,01205 \\
\hline 13 & 0,00603 & 0,00603 & 0,00603 \\
\hline 14 & 0,00602 & 0,01205 & 0,00602 \\
\hline 15 & 0,00603 & 0,01205 & 0,00603 \\
\hline 16 & 0,00602 & 0,0241 & 0,06602 \\
\hline 17 & 0,00603 & 0,03615 & 0,03603 \\
\hline $18 \ldots$ & 0,00602 & 0,0482 & 0,00602 \\
\hline 19 & 0,00121 & 0,0723 & 0,00121 \\
\hline 20 & 0,00120 & 0,0964 & 0,00120 \\
\hline 21 & 0,00121 & 0,1687 & 0,00121 \\
\hline 22 & 0,00120 & 0,0964 & 0,00120 \\
\hline 23 & 0,00121 & 0,2651 & 0,00121 \\
\hline 24 & 0,00241 & 0,0964 & 0,00241 \\
\hline 25 & 0,00346 & 0,0241 & 0,00346 \\
\hline
\end{tabular}


Para o padrão 4 desenvolveu-se um programa especifico (EP5DMFR), que aparece no apêndice 2 , onde a rotina de entrada relativa aos índices de esporos efetivos foi suprimida. Neste programa o câlculo da quantidade de tecido la tente (XL(M)) é obtida a partir da multiplicação da quantida de total de tecido infeccioso SI(M) pela quantidade de esporos efetivos produzidos (MD) e corrigidos pelo fator de con : tenção (co), conforme preconizado por ZADoks (1971).

os padrões 1,2 e 3 foram simulados com o emprego do programa EP6DMFRPL. (Apêndice 1), onde existe uma rotina de entrada dos índices de esporos efetivos (MV) e o respectivo cälculo do nümero de esporios efetivos (MD) que ë obtido pela multiplicação do indice MV pela quantidade total de esporos (PT). A quantidade de tecido latente é obtida pela multiplicação de cada tecido infeccioso (XI) pela respectiva quantidade de esporos efetivos (MD) e corrigidos, pelo fator de contenção (CD). 


\section{4 - RESULTADOS}

4.1. Verificação do modelo

Os valores simulados obtidos a partir dos parâmetros epidemiológicos constantes na Tabela 1 estão representados na Figura 4, tendo a quantidade total de doença sido transformada em porcentagem.

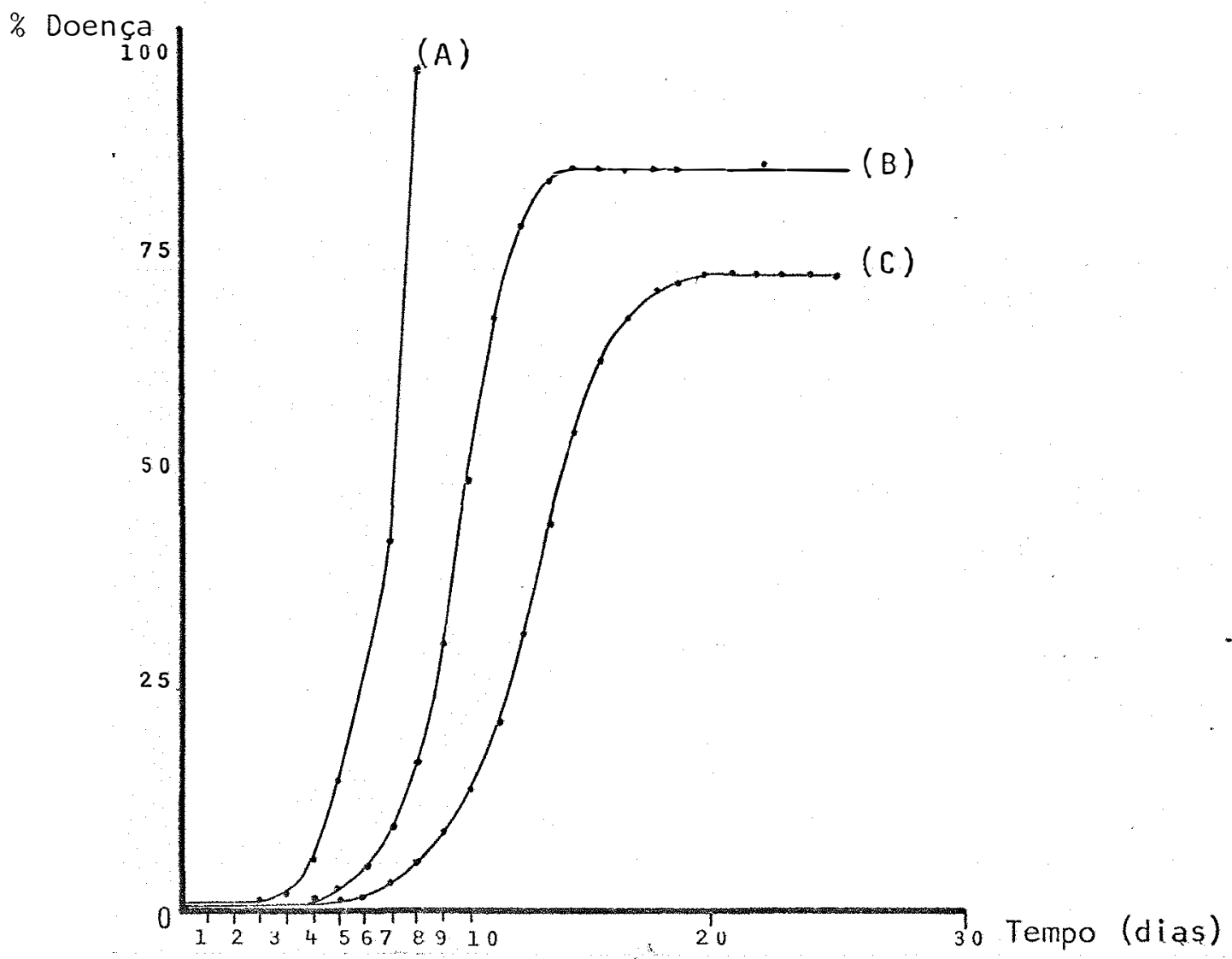

Figura 4 - Curvas de progresso de epidemias, em porcentagem de tecido doen te por tempo em dias, obtidas a partir dos seguintes parâmetrōs epidemiológicos $A=$ Período latente $(P L)=4$ dias; Período infeccioso $(P \mid)=4$ dias e Taxa bäsica de infecção corrigida $\left(R_{C}\right)=$ 16 unidades $/ \mathrm{dia} ; B=\left(P L=1\right.$ dia; $P I=1 \mathrm{dia} ; R_{C}=2$ Unidades $\left./ \mathrm{dia}\right)$ e $C=\left(P L={ }_{3} 1\right.$ dia; $P I=1$ dia; $R_{C}=1,7$ unidade/dia $)$. Tecido disponível $5 \times 10^{3}$ unidades. 
A quantidade de inöculo inicial $\left(x_{0}-\right.$ coeficiente linear) e taxa aparente de infecção ( $r$ - coeficiente angular) assim como o coeficiente de correlação $\left(R^{2}\right)$ cal culados a partir de anälise de regressão linear dos dados transformados em logito, obtidos pela simulação dos parâmetros epidemiológicos constantes na Tabela 2 , estão sumarizados na Tabela 5. Acrescentou-se, a inda, nesta mesma tabela,o tempo necessário para a epidemia simulada atingir $50 \%$ de área foliar.

Tabela 5 - Parâmetros epidemiolögicos inôculo inicial $\left(x_{0}\right)$.., taxa aparente de infeção $(r)$ e os respectivoscoe ficientes de correlação $\left(R^{2}\right)$ calculados por regressão linear dos dados transformados em logito, obtidos pela simulação com parâmetros epidemiológicos da tabela 2. Consta, ainda o tempo necessário para epidemia atingir $50 \%$ de ärea foliar. Tecido disponível $5 \times 10^{13}$ unidades.

\begin{tabular}{|c|c|c|c|c|}
\hline & $\cdot x_{0}$ & r. & $R^{2}$ & T. $50 \%$ \\
\hline Sis tema & $\begin{array}{c}\% \text { área foliar } \\
\text { doente }\end{array}$ & $\begin{array}{l}\text { Unidades } \\
\text { por dia }\end{array}$ & & Dias \\
\hline $\begin{array}{c}\text { infestans } \\
\text { batata }\end{array}$ & $-30,6013$ & 0,48443 & 0,998 & 56,5 \\
\hline $\begin{array}{l}\text { P. graminis } \\
\text { trigo }\end{array}$ & $-28,8714$ & 0,45669 & 0,999 & 56,5 \\
\hline
\end{tabular}


4.2. Simulação do efeito de alterações no período infecc i oso

os valores relativos à simulação do efeito de alterações no período infeccioso foram transformados em logito e calculadas as regressões lineares cujos parâmetros epidemiológicos quantidade efetiva de inöculo inicial ( $x_{0}$ coeficiente linear).e taxa aparente de infecção $(r$ - coefi ciente angular) aparecem na Tabela 6. Acrescentou-se, ainda, nesta mesma tabela, o coeficiente de correlação $\left(R^{2}\right)$ e o tem po estimado para a epidemia simulada atingir $50 \%$ e $99 \%$ de àrea foliar.

A representação grä́ica das regressões lineares estão na Figura 5 .

Posteriormente as quantidades de tecido doente em porcentagem foram transformadas em logarítmo Neperiano e estão representadas na Figura 6 . 
Tabela 6 - Tempo aproximado para atingir 50\% e $99 \%$ de tecido doente e estimativas da quantidade efetiva de inó culo inicial ( $\left.X_{O}\right)$, da taxa aparente de infecçãdr) e do coeficiente de correlação $\left(R^{2}\right)$ da reta obtida por regressão linear a partir da simulação do efeito de alterações no período infeccioso(PI), com período latente $(P L=4$ dias) e taxa basica. de infeç̧ão corrigida ( $R c=16$ uniciades/dia). Tecido disponível $5 \times 10^{13}$ unidades.

\begin{tabular}{cccccc}
\hline PI & $\begin{array}{c}\mathrm{X}_{0} \\
\text { area foliar } \\
\text { duente }\end{array}$ & $\begin{array}{c}\mathrm{r} \text { Inidades } \\
\text { por dia }\end{array}$ & $R^{2}$ & T 50\% & T 99\% \\
\hline 1 & $-30,39233$ & 0,69291 & 0,996 & - & 44,5 \\
2 & $-30,14807$ & 0,79273 & 0,999 & 37,5 & 38,5 \\
4 & $-30,04988$ & 0,83132 & 1,000 & 35,5 & 35,5 \\
8 & $-30,08833$ & 0,84099 & 1,000 & 35,5 & 36,5 \\
16 & $-30,09046$ & 0,84132 & 1,000 & 35,5 & 36,5 \\
25 & $-30,09046$ & 0,84132 & 1,000 & 35,5 & 36,5 \\
\hline
\end{tabular}




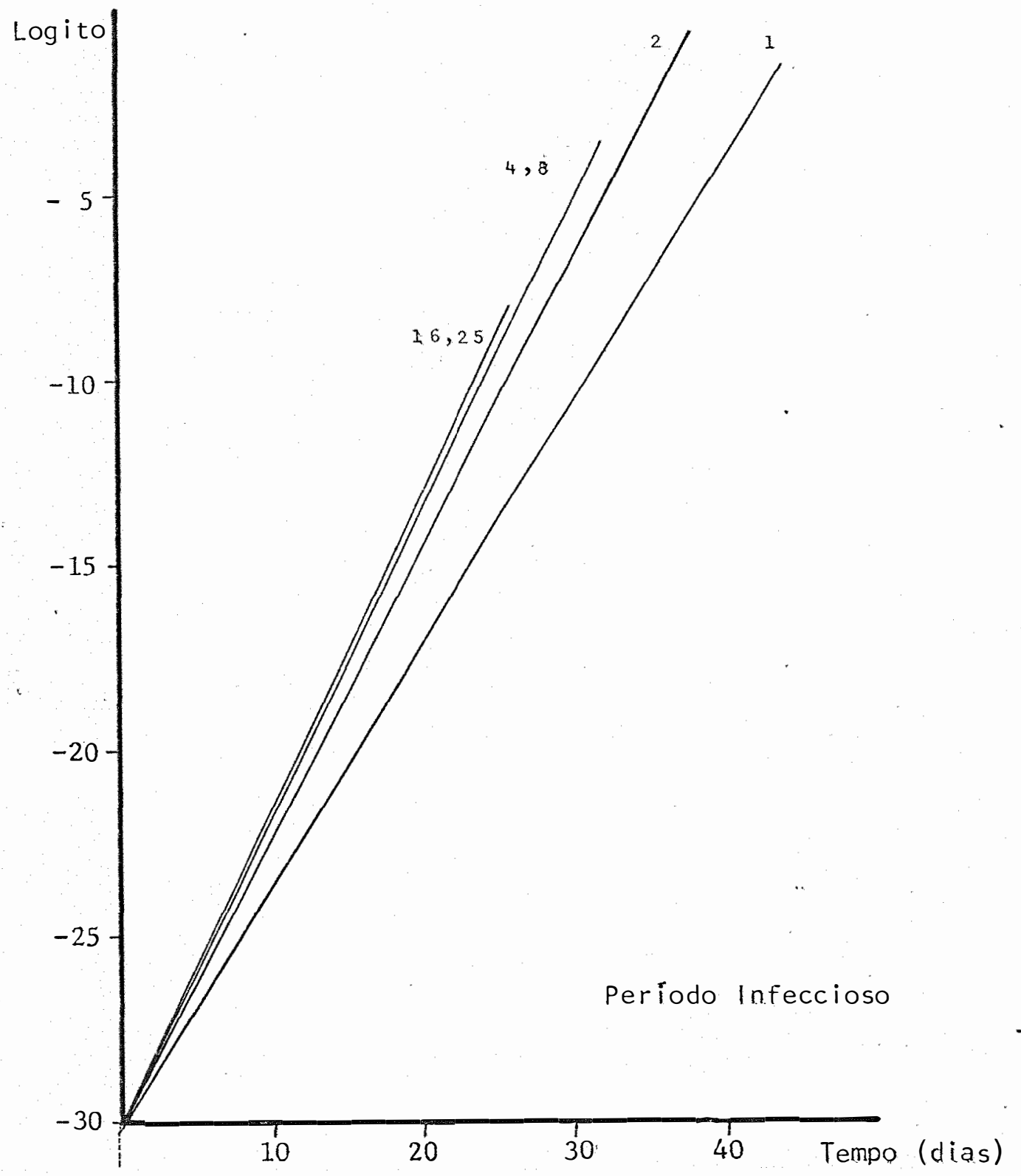

Figura 5 - Representação das retas obtidas a partir dos coeficientes assinalados na Tabela 6 , em função do efeito simula do de alteraçōes no valor do período infeccioso $(P /),=$ mantendo-se tanto o periodo latente $(P L=4$ dias)como 7 taxa básica de infecção corrigida ( $R_{c}=16$ unidades/dia ) constantes. Tecido disponivel $5{ }^{c} \times 10^{13}$ unidades. 
$\ln (\%$ doença)

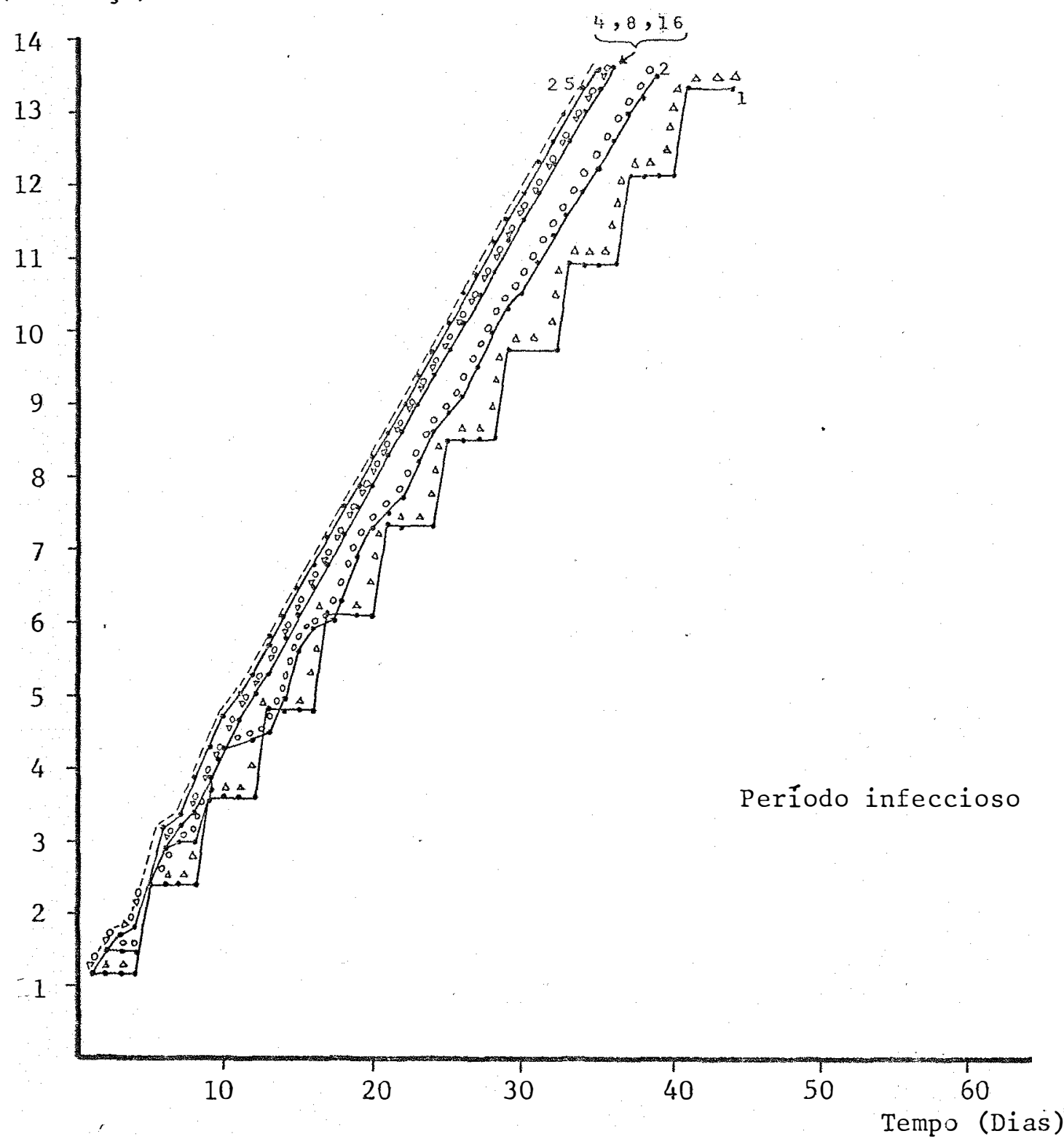

Figura 6. Curvas de progresso de epidemias obtidas em função do efeito simulado de alterações no valor do período infeccioso (PI), mantendo-se tanto o período latente ( $\mathrm{PL}=4$ dias) como a taxa bäsica de infecção corrigida $\left(R_{c}=16\right.$ unidades/dia) constantes. Dados transformados em logarítmo neperiano da porcentagem de doença. Tecido disponível $5 \times 10^{13}$ unidades. 
4.3. Simulação do efeito de alterações no período latente

os valores relativos à. simulação do efeito de alterações no período latente foram transformados em logi to e calculadas as regressões lineares cujos parâmetros epidemiológicos quantidade efetiva de inóculo inicial ( $x_{0}$ - coe ficiente linear) e taxa aparente de infecção ( $r$ - coeficiente angular) aparecem na Tabela 7. Acrescentau-se, ainda, nes ta mesma tabela, o coeficiente de correlação $\left(R^{2}\right)$ e o tempo es timado para a epidemia simulada atingir $50 \%$ e $99 \%$ de ärea fo liar.

A representação gräfica das regressões lineares estão na Figura 7 .

Posteriormente as quantidades de tecido doente em porcentagem foram transformadas em logarítmo neperiano e estão representadas na Figura 8. 
Tabela 7 - Tempo aproximado para atingir 50\% e 99\% de tecido doente e as estimativas da quantidade efetiva de inöculo inicial ( $x_{0}$ ), da taxa aparente de infecção $(r)$ e do coeficiente de correlação $\left(R^{2}\right)$ da reta obtida por regressão linear a partir da simu lação do efeito de alteraçóes no período latente $(P L)$, com período infeccioso ( $P \mid=8$ dias) e taxa bäsica de infecção corrigida (Rc $=16$ unidades / dias). Tecido disponível $5 \times 10^{13}$ unidades.

\begin{tabular}{cccccc}
\hline PL & $\begin{array}{c}\mathrm{X}_{0} \\
\% \text { area foliar }\end{array}$ & $\begin{array}{c}r \\
\text { Unidades/dia }\end{array}$ & $R^{2}$ & $\begin{array}{c}\text { T } 50 \% \\
\text { dias }\end{array}$ & $\begin{array}{c}\text { T } 99 \% \\
\text { dias }\end{array}$ \\
\hline 1 & $-31,73572$ & 2,88158 & 1,00 & 10,5 & 11,5 \\
4 & $-30,08833$ & 0,88099 & 1,00 & 35,5 & 36,5 \\
8 & $-29,52123$ & 0,46656 & 1,00 & $>60$ & $>60$ \\
12 & $-29,27564$ & 0,32994 & 1,00 & $>60$ & $>60$ \\
16 & $-29,13398$ & 0,25604 & 1,00 & $>60$ & $>60$ \\
\hline
\end{tabular}




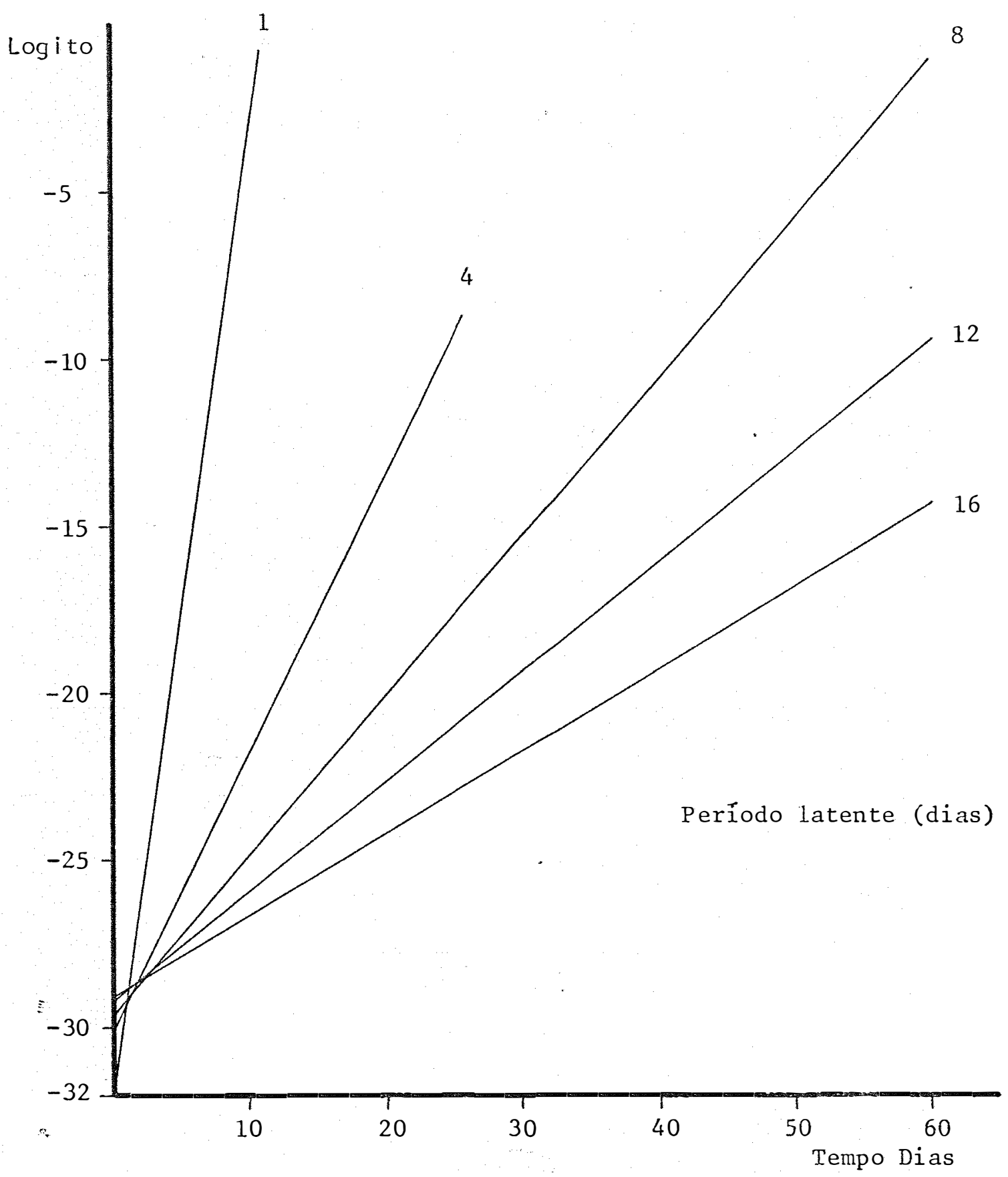

Figura 7. Representação das retas obtidas a partir dos coeficientes assinalados na Tabela 7 , em função do efeito simulado de alterações no valor do período latente (PL), mantendo-se tanto o período infeccioso ( $\mathrm{PL}=8 \mathrm{dias)}$ como a taxa bäsica de infeç̧ão corrigida $\left(R_{c}=16\right.$ unidades/dias $)$ constantes. Tecido disponíve1 5 × $10^{13}$ unidades. 
$\ln (\%$ doença)

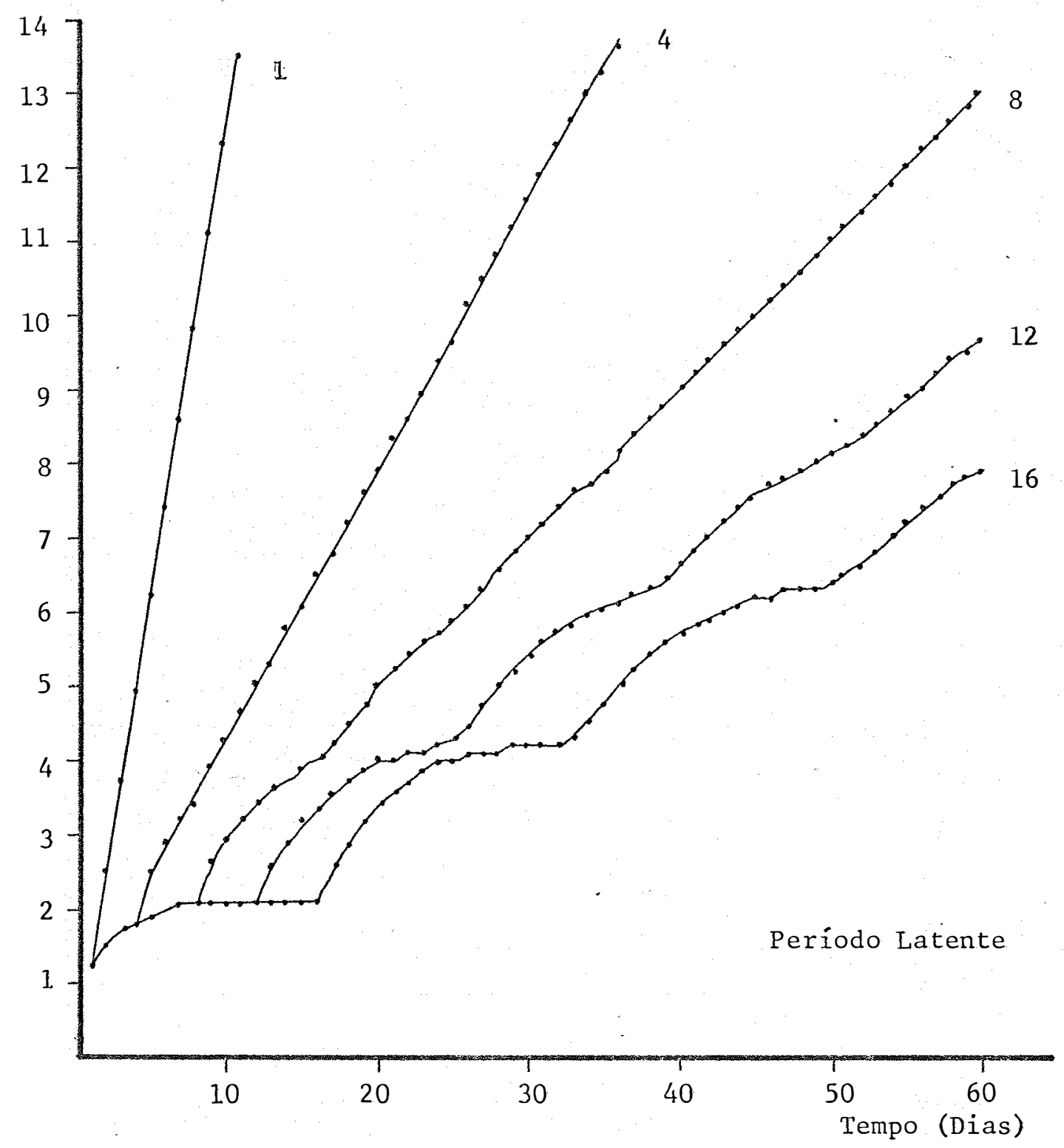

Figura 8. Curvas de progresso de epidemias obtidas em função do efeito simulado de alterações no valor do período latente (PL), man tendo-se tanto o período infeccioso ( $\mathrm{PI}=8 \mathrm{dias}$ ) como a taxa básica de infeç̧ão corrigida ( $R_{c}=16$ unidades/dia) constantantes. Dados transformados em logaritmo neperiano da porcentagem de doença. Tecido disponive1 $5 \times 10^{13}$ unidades. 
4.4. Simulação do efeito de alterações na quantidade de tecido disponível

os valores relativos à simulação do efeito de alterações na quantidade de tecido disponível foram trans formados em logito e calculadas as regressões lineares cujos parâmetros epidemiológicos quantidade efetiva de inóculo ini cial ( $x_{0}$ - coeficiente linear) e taxa aparente de infecção ( $r$ - coeficiente angular) aparecem na Tabela. 8. Acrescentouse, ainda, nesta mesma tabela, o coeficiente de correlação $\left(R^{2}\right)$ e o tempo estimado para a epidemia simulada atingir $50 \%$ e $99 \%$ de àrea foliar.

A representação gräfica das regressões lineares estão na Figura 9.

Posteriormente as quantidades de tecido doente em porcentagem foram transformadas em logarítmo neperiano e estão representadas na Figura 10. 
Tabela 8 - Tempo aproximado para atingir 50\% e 99\% de tecido doente e as estimativas da quantidade efetiva de inóculo inicial ( $X_{0}$ ), da taxa aparente de infecção $(r)$ e do coeficiente de correlação $\left(R^{2}\right)$ da reta obtida por regressão linear a partir da simu lação do efeito de alterações na quantidade de te cido disponível ( $S V$ ) com período latente ( $P L=4$ dias) e taxa bāsica de infecção corrigida ( $R c=10$ unidades/dia).

\begin{tabular}{|c|c|c|c|c|c|}
\hline SV & $\%$ ärea foliar & Un idades/dia & $R^{2}$ & $\begin{array}{r}5.0 \% \\
\text { dias }\end{array}$ & $\begin{array}{r}\text { T 99\% } \\
\text { dias }\end{array}$ \\
\hline $5 \times 10^{3}$ & $-7,56172$ & 1,03698 & 0,947 & 8,5 & 9,5 \\
\hline $5 \times 10^{6}$ & $-14,00669$ & 0,85256 & 0,997 & 16,5 & 17,5 \\
\hline $5 \times 10^{8}$ & $-19,67663$ & 0,89286 & 1,000 & 21,5 & 23,5 \\
\hline $5 \times 10^{13}$ & $-30,04988$ & 0,83132 & 1,000 & 35,5 & 36,5 \\
\hline
\end{tabular}




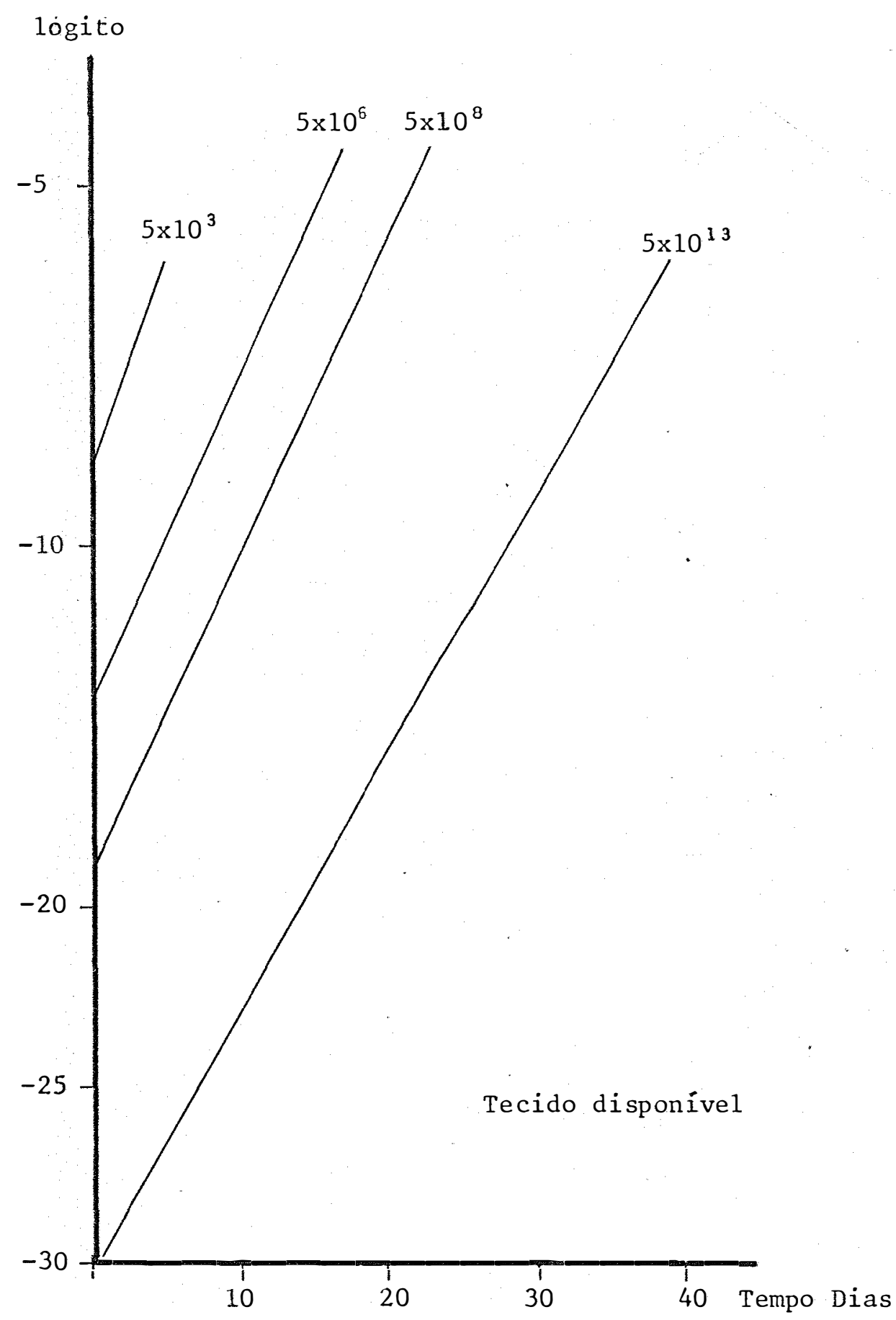

Figura 9. Representação das retas obtidas a partir dos coeficientes assinalados na tabela 8 , em função do efeito simulado de alterações no valor da quantidade de tecido disponível, mantendo-se tanto o período latente $(\mathrm{PL}=4$ dias) como o período infeccioso $(\mathrm{PI}=$ $=4$ dias) e a taxa básica de infecção corrigida $\left(R_{C}=10\right.$ unidades/dia) constantes. 
$\ln (\%$ doença)

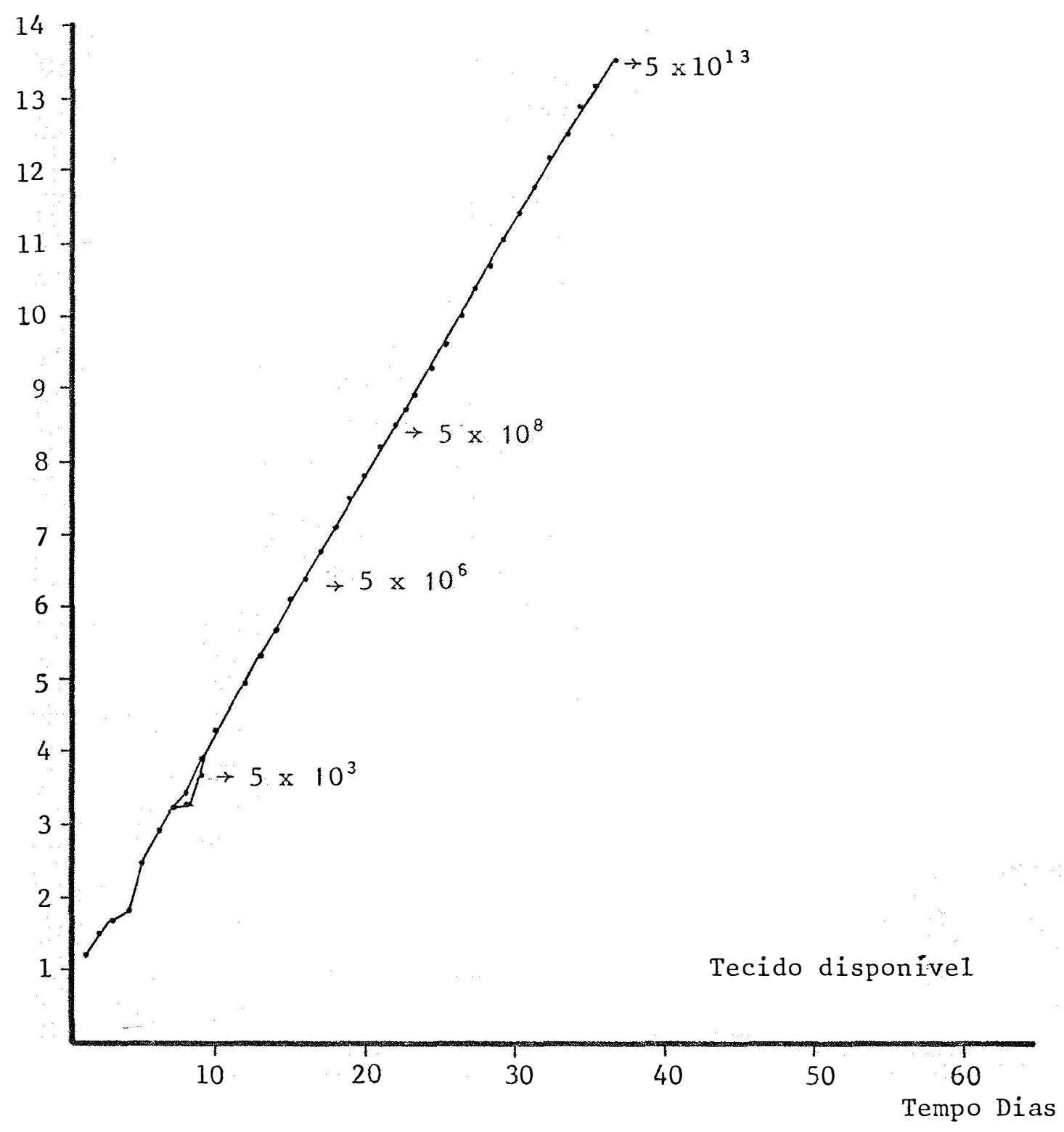

Figura 10. Curvas de progresso de epidemia obtidas em função do efeito simulado de alterações no valor da quantidade de tecido dis poníve1 (SV), mantendo-se tanto o período infeccioso ( $\mathrm{PI}=$ $=4$ dias), como o período 1 atente ( $P L=4$ dias) e a taxa bäsica de infeç̧ão corrigida ( $R_{C}=10$ unidades/dia) constantes. Dados transformados em logarítmo neperiano da porcentagem de doença. 
4.5. Simulação do efeito de padrões de produção de esporos com período infeccioso de 8 dias.

os valores relativos à simulação do efeito de padrões de produção de esporos com período infeccioso de 8 dias foram transformacios em 1 ogito e calculadas as regressões lineares cujos parâmetros epidemiológicos quantidade efetiva de inóculo inicial ( $x_{0}$ - coeficiente linear) e taxa a parente de infecção ( $r$ - coeficiente angula.r) aparecem. na Tabela 9. Acrescentou-se, ainda, nesta mesma tabela, o coefí ciente de correlação $\left(R^{2}\right)$ e o tempo estimado para a epidemia simulada atingir $50 \%$ e $99 \%$ de ärea foliar.

A representaçäo gräfica das regressões $1 i$ neares estão na Figura 1 i.

Posteriormente as quantidades de tecido doente em porcentagem foram transformadas em logarítmo neperiano e estão representadas na Figura 12 . 
Tabela 9 - Tempo aproximado para atingir 50\% e 99\% de tecido doente e estimativas da quantidade efetiva de inö culo inicial (Xo) da taxa aparente de infecção(r) e do coeficiente de correlação $\left(R^{2}\right)$ da reta obtida por regressão linear a partir da simulaçãodo efeito de 4 padrões de produção de esporos efeti vos, com período infeccioso de 8 dias, período la tente ( $P L=4$ dias) e taxa bāsica de infeç̧ão cor rigida $(R c=16$ unidades/dia). Tecido disponível $5 \times 10^{13}$ unidades.

\begin{tabular}{cccccc}
\hline PAdRões & $\begin{array}{c}x_{0} \\
\% \text { árealfoliar }\end{array}$ & $\begin{array}{c}r \\
\text { unidades/dia }\end{array}$ & $R^{2}$ & $\begin{array}{c}\text { T 50\% } \\
\text { dias }\end{array}$ & $\begin{array}{c}T \text { 99\% } \\
\text { dias }\end{array}$ \\
\hline 1 & $-29,87743$ & 1,11937 & 0,996 & 26,5 & 28 \\
2 & $-31,31432$ & 0,52657 & 1,000 & 58,5 & 61,5 \\
3 & $-30,02424$ & 0,89670 & 0,999 & 33,5 & 34,5 \\
4 & $-30,08833$ & 0,84099 & 1,000 & 35,5 & 36,5 \\
\hline
\end{tabular}


.60.

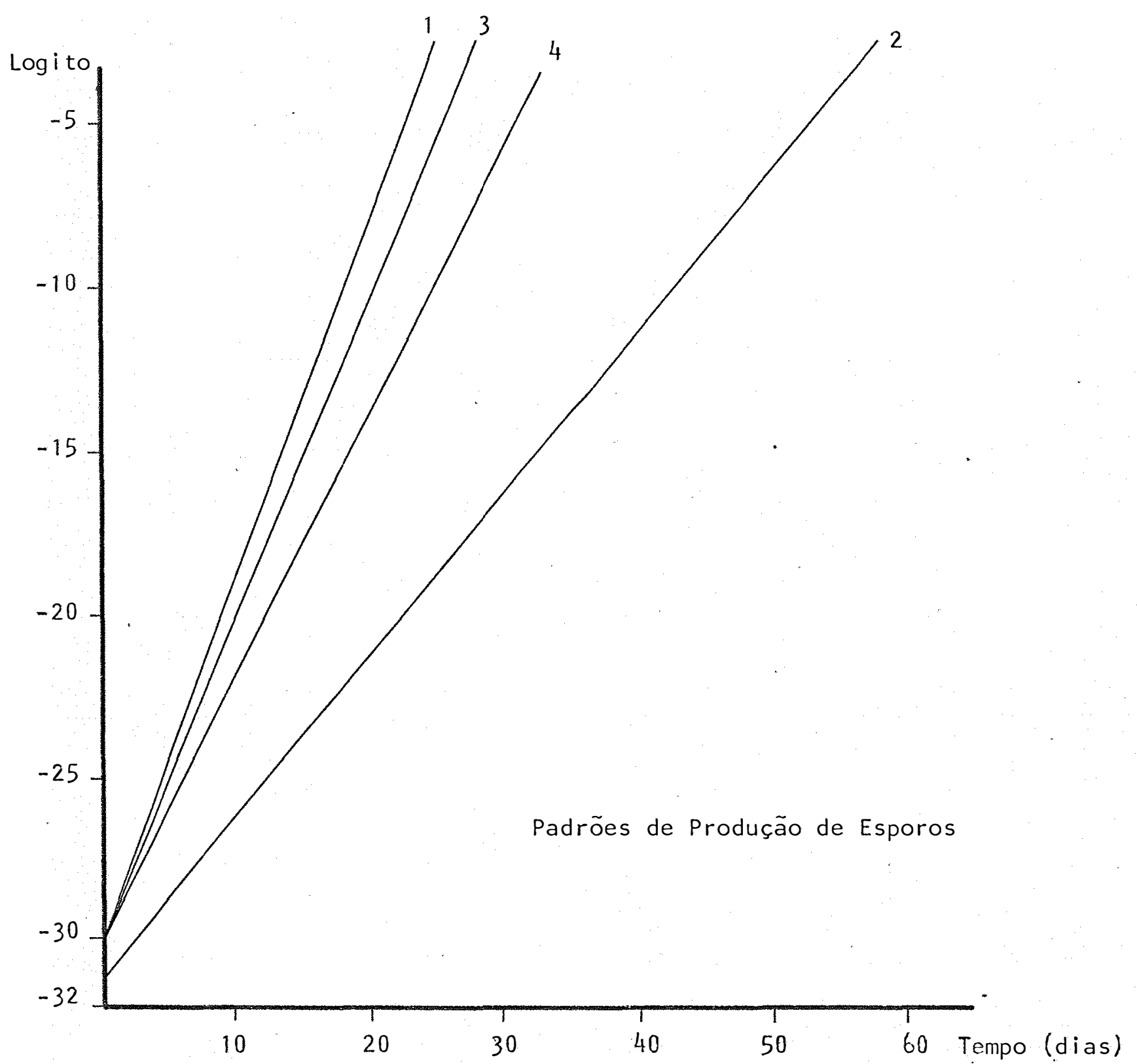

Figura 11 - Representação das retas obtidas a partir dos coeficientes assinalados na Tabela 9, em função do efeito simulado de padrões de produçăo de esporos com período enfeccioso de 8 dias, mantendo-se tanto o período latente ( $\mathrm{PL}=4$ dias) como a taxa bássica de infecção cor rigida $\left(R_{c}=16\right.$ unidades/dia) constantes. Tecido disponível $5 \times 10^{13^{-}}$ unidades. $C$ 


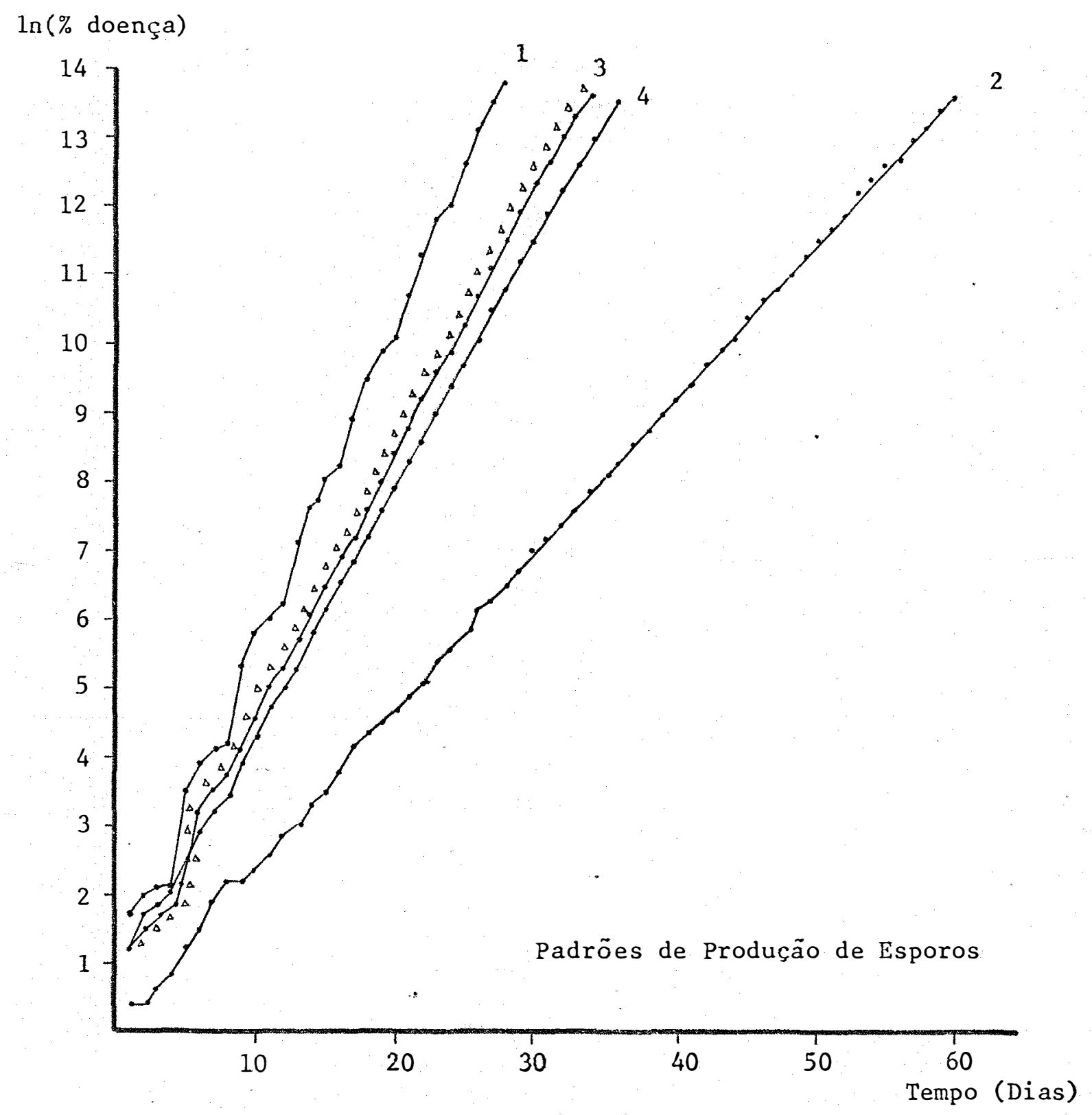

Figura 12. Curvas de progresso de epidemias obtidas em função do efeito simulado de padrões de produção de esporos com período infec cioso de 8 dias, mantendo-se tanto o período latente ( $\mathrm{PL}=$ $=4$ dias $)$ como a taxa básica de infecção corrigida $\left(R_{c}=\right.$ $=16$ unidades $(\mathrm{dia})$ constantes. Dados trasformados em logaritmo neperiano da porcentagen de doença. Tecido disponível $.5 \times 10^{13}$ unidades. 
4.6. Simulação do efeito de padrões de produção de esporos com período infeccioso de 25 dias

os valores relativos à simulação do efeito de padrões de produção de esporos com período infeccioso de 25 dias foram transformados em logito e calculadas as regres sões lineares cujos parâmetros epidemiológicos quantidade efetiva de inóculo inicial ( $x_{0}$ - coeficiente linear) e taxa aparente de infecção ( $r$ - coeficiente angulạr) aparecem na Tabela 10. Acrescentou-se, ainda, nesta mesma tabela, o coeficiente de correlação $\left(R^{2}\right)$ e o tempo estimado para a epidemia simulada atingir $50 \%$ e $99 \%$ de ärea foliar.

A representação grä́fica das regressões $1 \mathfrak{i}$ neares estão na Figura 13.

Posteriormente as quantidades de tecido doente em porcentagem foram transformadas em logaritmo neperiano e estão representadas na Figura 14. 
Tabela 10 - Tempo aproximado para atingir 50\% e 99\% de teci do doente e estimativas da quantidade efetiva de inöculo inicial ( $x_{0}$ ) da taxa aparente de infecção $(r)$ e do coeficiente de correlação $\left(R^{2}\right)$ da reta obtida por regressão linear a partir da simulação do efeito de 4 padrões de produção de es poros efetivos, com período infeccioso de 25 dias, periodo latente $(P L=4$ dias $)$ e taxa bäsica de infecção corrigida $(R c=16$ unidades/dia). Tecido disponivel $5 \times 10^{13}$ unidades.

\begin{tabular}{cccccc}
\hline Padrões & $\begin{array}{c}\mathrm{X}_{0} \\
\% \text { ärea foliar }\end{array}$ & $\begin{array}{c}r \\
\text { unidades/dia }\end{array}$ & $R^{2}$ & $\begin{array}{r}\text { To\% } \\
\text { dias }\end{array}$ & $\begin{array}{r}\text { T } 99 \% \\
\text { dias }\end{array}$ \\
\hline 1 & $-30,22314$ & 0,97964 & 0,997 & 30,5 & 32,5 \\
2 & $-31,36788$ & 0,34214 & 1,000 & $>60$ & $>60$ \\
3 & $-30,06682$ & 0,92308 & 0,999 & 32,5 & 33,5 \\
4 & $-30,09046$ & 0,84132 & 1,000 & 35,5 & 36,5 \\
\hline
\end{tabular}




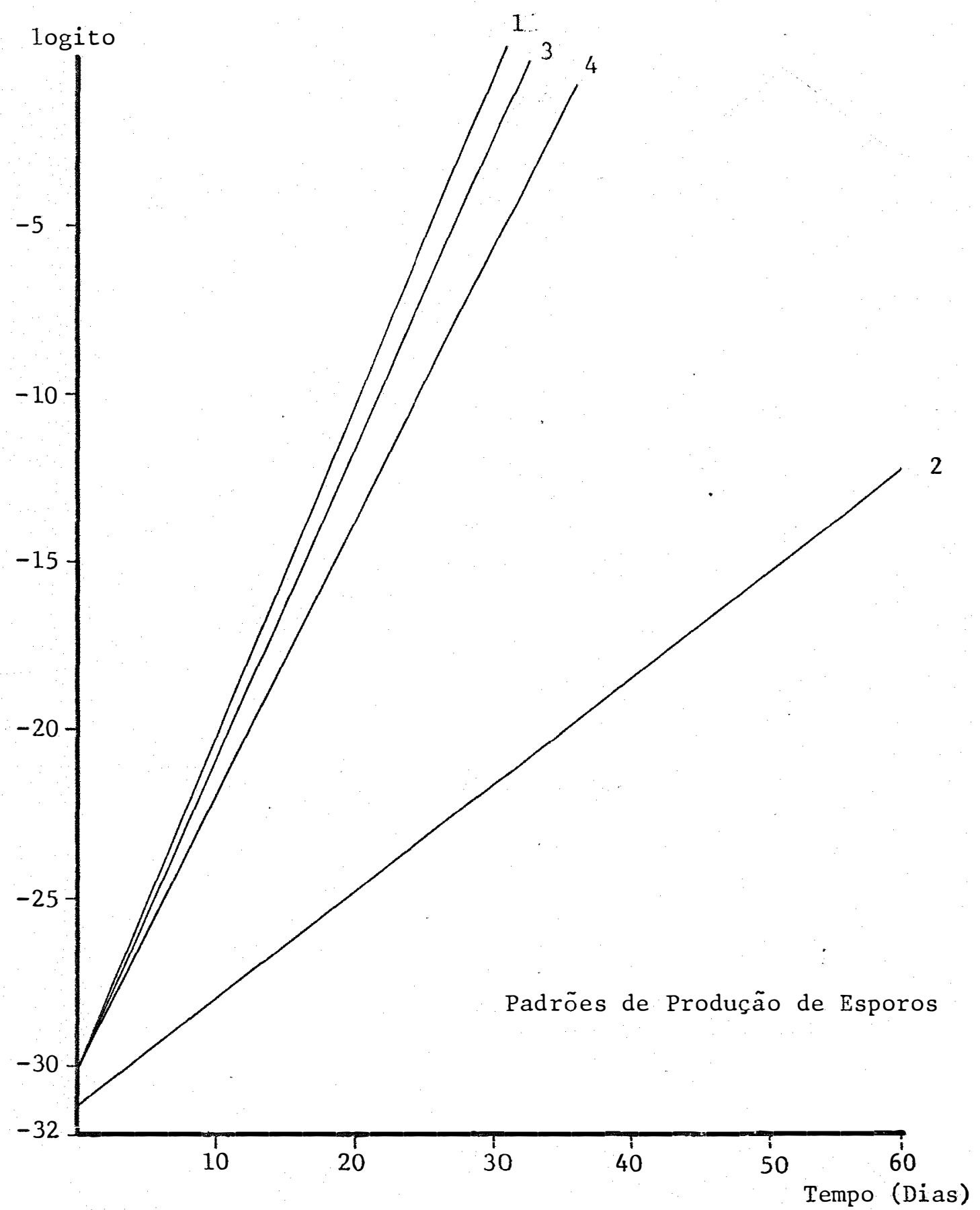

Figura 13. Representação das retas obtidas a partir dos coeficientes assinalados na tabela 10 , em função do efeito simulado de padrões de produção de esporos com período infeccioso de 25 dias, mantendo-se tanto o período latente ( $\mathrm{PL}=4$ dias) como a taxa bāsica de infecção corrigida $\left(R_{c}=16\right.$ unidades/ /dia) constantes. Tecido disponível $5 \times 10^{13^{\mathrm{C}}}$ unidades. 
In (\% doença)

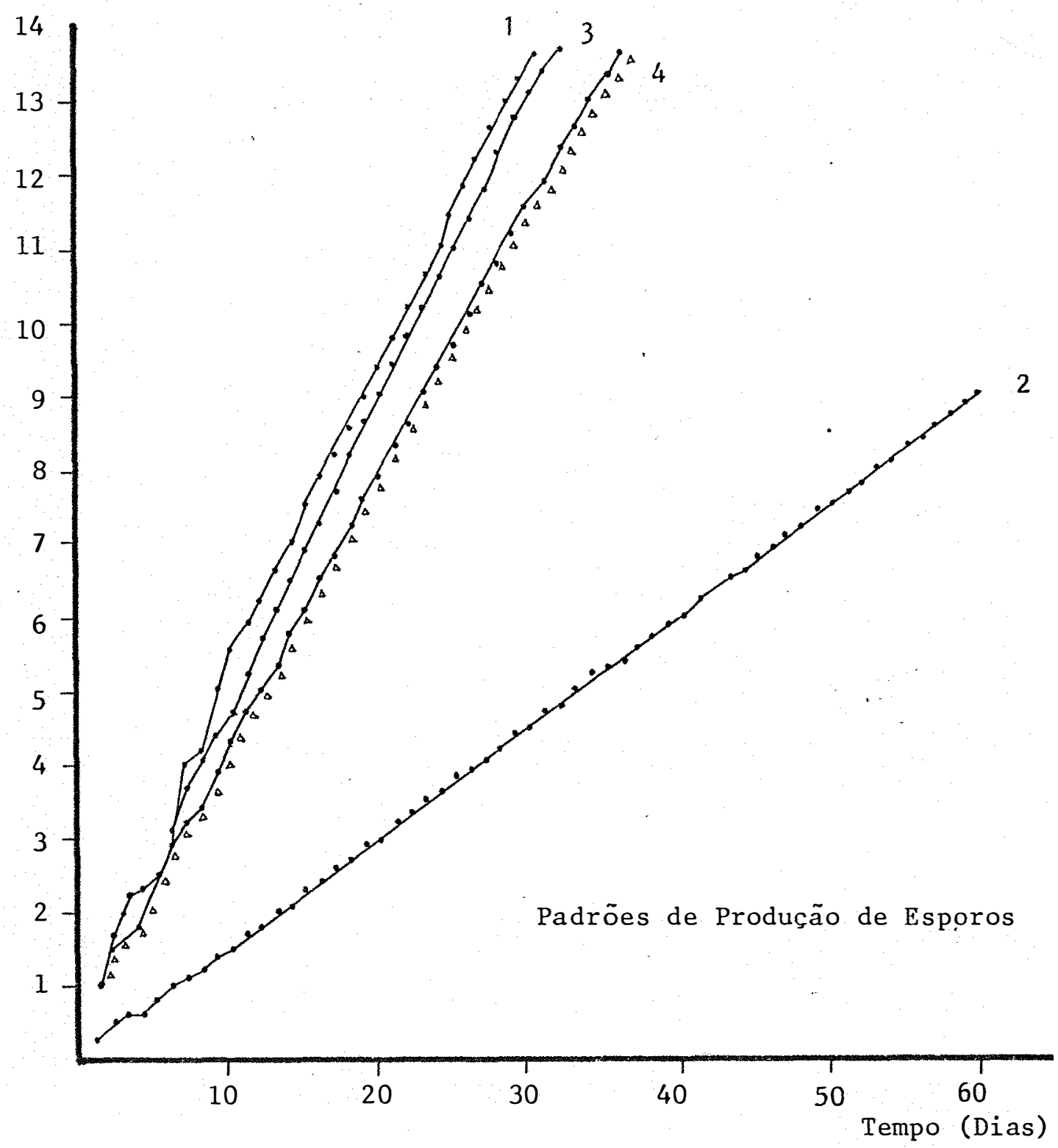

Figura 14. Curvas de progresso de epidemias obtifas em função do efeito simulado de padrões de produção de esporos com período infeccioso de 25 dias, mantendo-se tanto o período latente $(\mathrm{PL}=4$ dias $)$ como a taxa básica de infeç̧ão corrigida $\left(\mathrm{R}_{\mathrm{c}}=\right.$ $=16$ unidades (dia) constantes. Dados transformados em 1ogaritmo neperiano da porcentagem de doença. Tecido disponível $5 \times 10^{3}$ unidades. 
.66 .

\section{DISCUSSĀO}

5.1. Elaboração de modelos de simulação

Hä pelo ao menos duas linhas para o desenvolvimento de modelos de simulação de doenças. A primeira referesse ao grupo de simuladores que tiveram por base o mo delo proposto por WAGGONER e HORSFALL (1969) para o sistema Alternaria solani - tomate, conhecido por EPIDEM. Nestes modelos a simulação esta baseada na cadeia de infecção, proposta originalmente por GAUMANN (1950) e cuja representação modificada se encontra na Figura 1. Procura-se, desta forma, descrever o sistema patógeno-hospedeiro incorporando-se o maior nümero possível de variäveis do ambiente. A maioria 
desses modelos säo unidimensionais uma vez que o progresso da quantidade de doença è analisada somente em função do tempo. Neste caso estão os modelos EPIMAY (WAGGONER et ali $i$, 1972) Helminthosporium maydis - milho; EPISIM (ZADOKS e RIJSDIJK, 1972) - Puccinia striiformis - trigo; EPIVEN (KRANZ et alii, 1973) = Venturia inaequalis - maçã.

A incorporação de dimensões do espaço na a nälise do progresso de doença, neste tipo de modelo, foi realizado por SHRUM (1975) - EPIDEMIC. Alëm disso, o autor criou os chamados "funis de informações" que permitem que o mesmo programa possa ser utilizado, conforme a disponibilidade de dados, por qualquer s istema patögeno-hospedeiro que siga uma dinâmica semelhante às ferrugens, míldios, car vões, oídios e algumas manchas foliares. Procurou-se, desta. forma, eliminar o constante trabalho de se estar reescreven do programas à medida que novos conjuntos de variáveis sejam acrescidos ou suprimidos do modelo.

$$
\text { Parâmetros epídemiolögicos do do sistema }
$$

Uromyees phaseoli $\sim$ feijão estão sendo obtidos para serem incorporados ao EPIDEMIC, originalmente escrito para o sistema Puccinia strifformis - trigo, por um grupo de pesquisa dores da Universidade Estadual de Carolina do Norte nos Estados Unidos da América do Norte (IMHOFF et alii, 1982). 
A etapa da cadeia de infeç̧ão, que vai da geração de esporos a novas infecções, passando pela dissemi nação, inoculação, germinação e penetração, é que tem gerado maiores erros nos resultados obtidos pelas simulacões nos modelos até agora publicados. Tentativa de superar essa li mitação estā sendo, realizada com o modelo EPIGRAM et alii, 1983), para o sistema Erysiphe graminis fsp hordey cevada. Para tanto, os autores substituíram essas etapas da simulação pela quantificação do nūmero de ésporos efetivos na cultura através de plantas armadilhas que, colocadas na parcela em estudo, recebem naturalmente os s esporos de Erisiphe graminis. Posteriormente os mesmos são quantificados com auxilio de resina especial. 0 valor obtido passa a ser uma das entradas do sistema que a partir dessa etapa é semelhante a todos os outros da familia EPIDEM.

Outra linha para elaboração de model os foi a adotada por ZADOKS (1971), baseado na equação diferencial proposta por VAN DER PLANK (1963) e discutido no item 3.1.1. deste trabalho: Este tipo de modelo fundamenta-se nos principais parâmetros que constituem uma, epidemia: tecido dispo nível, em latēncia, infeccioso e removido. 0 modelo supõe como constante o nümero de lesões filhas geradas por lesão mãe, ou seja, a taxa bãsica de infecção corrigida(Rc); o período latente (p) e o período infeccioso (i). os Éfatores do meio ambiente são incorporados ao sistema por meio 
de taxas. Enquanto elaborado de forma teörica tem por finalidade fornecer dados sobre o comportamento dos parâmetros epidemiológicos. Neste sentido, KAMPMEIJER e ZADOKS (1977) escreveram o modelo EPIMUL que teve por finalidade acrescen tar a dimensão de espaço no modelo de ZADOKS (1971).

Parâmetros epidemiológicos relativos ao sistema Puccinia striiformis - trigo foram incorporados ao modelo de ZADOKS (1971) por RIJSDISK (1975). Para tanto, da dos meteorológicos, de resistência e efeito de aplicação de fungicidas foram acrescentados ao sistema, tendo se obtido uma descrição razoavelmente precisa do processo epidemiológico (RIJSDISK, 1975).

Ainda dentro dessa mesma linha de elaboração de modelos, TENG et alii (1977), trabalhando com o sistema Puccinia hordei - cevada, desenvolveram um modelo onde a taxa bàsica de infeç̧ão coŕrigida, ao invës de ser um valor constante, ë simulada a partir de variäveis como libe ração de esporos, sobrevivência, deposição, germinação e penetração. A partir desse sistema inicial os autores pretendem criar um modelo padrão para ferrugem da cevada que serä validado com dados de campo de vários anos. Finalmente os autores pretendem adequar o modelo a situações específicas de produtores (TENG et aliz, 1978). 
Doenças e pragas do trigo estão sendo estü dadas a partir de um modelo desenvolvido na Universidade de Wagenigen, cuja. simulação de doenças seguem a modelo básico proposto por ZADOKS (1971) (TENG e ZADOKS, 1980). Este mode lo - EPIPRE - é comercial e já foi viendido a cooperativas holandesas e inglesas (KRANZ, 1984 - comunicação pessoal).

o presente trabalho é um desenvolvimentodo modelo proposto por ZADOKS (1971) e se constitue numa pri meira etapa para obtenção de modelos que simulem is istemas específicos patögeno-hospedeiro. Neste contexto, parâmetros epidemiológicos relàtivo a Úromyces phaseoli - feijão foram coletados (MENDES, 1985) e numa fase posterior deverão ser incorporados ao sistema ora apresentado. No momento, o mode lo tem um caräter estritamente teörico, constituindo-se num instrumental básico para posterior desenvolvimento. Deve-se ressaltar que a linha divisöria entre os modelos de WAGGONER e HORSFALL (1969) e ZADOKS (1971) passa a ser tênue à medi da em que simplificações, atravês de taxas e parâmetros, são realizadas no primeiro modelo, como é o caso do EPIGRAM, ou, inversamente, detalhes são incorporados, como no modelo de-senvolvido por TENG et alii, 1977.

Deve-se ressaltar, ainda, que existe um grupo de pesquisadores que se utilizam das técnicas de elaboração de sistemas com a finalidade exclusivamente prediti va. Assim, afirmam que o importante-ē que o sistema seja ra 
zoavelmente preciso e possível a ser implantado a nivel de campo, de tal modo que um modelo que tenha uma precisão de 95\% a nível de laboratörio mas que não possa ser empregado em condições de campo devido à dificuldade de obtenção de dados, è menos util do que um simples modelo empírico que possa ser implementado mas tão somente com $80 \%$ de precisão (KRAUSE e MASSIE, 1975).

Exemplos dessa linha de desenvolvimento de modelos podem ser encontrados no sistema Puiccinia graminis tritici - trigo (EVERSMEYER et alii, 1973); Phytophthora infestans - batata (KRAUSE et alii, 1975; MACKENZIE, 1981); Puccinia striiformis - trigo (COAKLEY et alii, 1982).

\section{5,2. Verificação do modelo}

Os valores gerados pela equação diferencial descrita no item 3.1 .1 , e que serviu de arcabouço : teórico para que o presente modelo de simulação fosse elaborado, des crevem uma curva sigmôide quando representada graficamente. em escala decimal (VAN DER PLANK, 1963). Tal ocorre devido. ao fator de contenção $\left(1-x_{t}\right)$, onde $x_{t} \bar{e}$ a quantidade total de tecido doente, em porcentagem, que impõe um limite ao crescimento da curva. 
Desta forma, a anälise da Figura 4 demonstra que os valores gerados pelo sistema estão de acordo com o esperado quando representados em escala decimal. Para os valores de período latente e infeccioso de 1 dia e taxa básica de infeção corrigida de 1,7 e 2,0 unidades/dia o mode lo produziu uma assíntota indicando que a epidemia, para es ses valores de parâmetros epidemiolögicos, não tem condição de atingir $100 \%$ de tecido disponivel, o que foi anteriormen te descrito por VAN DER PLANK $(1975 ; 1982)$ : Pode-se obser var, também, que para os valores do período latente e infec cioso de 4 dias e com taxa bāsica de infecção corrigida de 16 unidades/dia a epidemia tem uma velocidade de crescimento muito acentuada e a assíntota não-ẽ observada, o que está de acordo com os trabalhos de ZADOKS (1971); TENG et alii (1977); ZADOKS E SCHEIN (1979).

A partir de valores de período latente $(p)$, período infeccioso (i) e da taxa aparente de infeção ( $r$ ), VAN DER PLANK (1963) calculou o valor da taxa bäsica de infecção corrigida ( $R c)$, dos sistemas Phytophthora infestansbatata e Puccinia graminis = trigo, por meio da expressão

$$
R_{C}=r \frac{e^{(i+p) r}}{e^{i r}-1}
$$


Dados simulados obtidos a partir dos valores de período latente, infeccioso e taxa básica de infecção corrigida relativos aos dois sistemas em questão, foram transformados em logito e calculados os coeficientes lineares e angulares da regressão linear. Este ültimo corresponde à taxa aparente de infeç̧ão $(r)$. A anālise da Tabela. 5 indica que os valores dessa taxa estão bastante proximos da queles originalmente empregados por VAN DER PLANK (1963), num processo inverso de cálculo. Essa segurida etapa do processo de verificação mostra que os dados gerados pelo modelo reproduzem aqueles obtidos pela equação diferencial da qual o modelo foi elaborado.

A quantidade de inöculo inicial $\left(x_{0}\right)$, correspondente ao coeficiente linear, não tem valor para verificação uma vez que é diretamente dependente da quantidade de tecido sadio disponível no início da simulação.

5.3. Simulação do efeito de alterações no período infeccioso

A simulação do efeito de alterações no período infeccioso foi realizada mantendo-se constante o período latente em 4 dias, a taxa bäsica de infecção corrigida em 16 unidades por dia, conforme Tabela 6. 0 período latente de 4 dias corresponde a encontrado no no sistema 
Phytophthora infestans - batata (VAN DER PLANK, 1963) e Puccinia hordei - cevada (TENG e CLOSE, 1978). Já a taxa bá sica de infecção corrigida é um valor arbitrário porém dentro de um intervalo possível uma vez que, por exemplo, para o sistema $P$. infestans - batata tem-se valor de 7 unidades/ dia e para P. graminis - trigo 36 unidades/dia, segundo cál culos de VAN DER PLANK (1963).

os valores do periodo infeccioso adotados para simulação tambëm encontram-se dentro de um intervalo factível pois a literatura cita: P. infestans.. - batata (VAN DER PLANK, 1963) - 1 dia; Puccinia graminis - trigo (VAN DER PLANK, 1963) - 10 dias; Hemileia vastatrix - café (BERGAMIN FILHO, 1983) - 15 dias; Puccinia hordei - cevada (TENG e CLOSE, 1978) - 4,18 e 24 dias, dependendo da tempe ratura.

A análise da Tabela 6 , feita com relação a os valores de taxa aparente de infecção, indica que o perío do infeccioso condiciona a velocidade de crescimento de uma epidemia enquanto este for menor que o valor do período latente. Assim, um período infeccioso de 1 dia e um péríodo latente de 4 dias geraram uma epidemia com taxa aparente de infecção de 0,69 unidades/dia. Porēm para um período infeccioso de 4 dias a epidemia atinge uma taxa aparente de infecção correspondente a 0,83 unidades/dia, valor este muito 
pröximo a 0,84 , unidades/dia relativo aos períodos infecciosos iguais e maiores que 8 dias. Este fato pode igualmente ser visualizado na Figura 5 , onde, a partir do período infeccioso de 4 dias, as retas coincidem, indicando não haver diferenças entre as epidemias simuladas. Esses dados mostram a importância do período latente para o modelo e já foi assinalado por ZADOKS (1971); TENG et azii (1977);ZADOKS e SCHEIN (1979).

A Figura 6 mostra que o péríodo infeccioso de 1 dia dâ origem a uma epidemia com crescimento descontínuo, o que está de acordo com o apresentado por ZADOKS (1971). Porém, a medida em que o valor do período infeccioso aumenta este fenômeno desaparece pois passa haver uma so breposição de tecidos infecciosos no tempo.

5.4. Simulação do efeito de. alterações no período latente

A simulação do efeito de alterações no período latente foi realizada mantendo-se constantes os valores do periodo infeccioso em 8 dias e a taxa bäsica de infeç̧ão corrigida em 16 unidades/dia. Conforme já apontado no item 5.3., ambos os valores são teöricos, porém factí veis, 
Exceção feita ao período latente de 1 dia, todos os outros valores empregados na simulação se aproximam de dados réais obtidos na literatura. Assim, temos 4 dias para o sistema $P$. infestans - batata (VAN DER PLANK, 1963); 7 -dias para Uromyces phaseoli - feijão (MENTEN, 1980; MENDES, 1985); 13 dias para P. hordei - cevada (TENG e CLOSE, $1978)$.

os valores da taxa aparente de infeçção, constantes da Tabela 7, indicam que o período latente è um parâmetro epidemiolögico que condiciona de forma acentuada a velocidade de crescimento da epidemia. Observa-se que a taxa aparente de infecção passou de 2,8 unidades/dia, quando o período latente era de 1 dia para, noutro éxtremo,0,25 unidades/dia quando este assumiu o valor de 16 dias. Há uma relação inversa entre o valor do período latente e a taxa aparente de infecção pois quando se dobra o período latente de 4 para 8 dias a taxa aparente se reduz por quase a metade, passando de 0,88 a 0,46 unidades/dia, numa relação de $1: 0,52,0$ mesmo se observa para os valores de 8 e 16 dias para período latente e 0,46-0,25 unidades/dia para taxa a pa rente de infeç̧ão, numa relação $1: 0,54$.

o efeito do período latente na evolução da epidemia também pode ser observado nas Figuras 7 e 8 . Na F gura 8 o atraso que o período latente provoca no desenvol- 
vimento da epidemia pode ser melhor visualizado quando se compara, por exemplo, os gräficos relativos ao período latente de 1 dia.com o de 16 dias. No primeiro caso a epidemia cresce numa linha reta pois o efeito do período latente é mínimo. Já no outro extremo existe uma fase em que a epidemia cresce enquanto dura o perf́odo infeccioso inicial. De corrido este espaço de tempo a epidemia entra numa assíntota e permanece como tal até que o período latente sejavencido, o que vai ocorrer no 179 dia. Deste valor até o 249 a epidemia cresce em função do valor do período infeccioso (8 dias). Após essa data e atë o 320 dia hä um novo patamar condicionado pelo período latente, quando a partir de então a intensidade dos patamares tende a diminuir. Este fenômeno se repete com menos intensidade à medida em que o valor do período latente diminui.

A importância do período latente para o de senvolvimento da epidemia jā havia sido anteriormente apontada por VAN DER PLANK, (1963); ZADOKS, (1971); TENG et alii, (1977); ZADOKS e SCHE[N, (1979).

5.5. Simulação do efeito de alterações na quantidade de tecido disponível

os valores relativos à simulação do efeito de alterações na quantidade de tecido disponível foram obt 
dos mantendo-se constantes o período latente em 4 dias, o infeccioso em 4 dias e a taxa bäsica de infeção corrigida em 10 unidades/dia.

A equação diferencial, na qual o modelo se baseou (item 3.1 .1$.$) , necessita que os valores estejam em$ porcentagem. Assim, o efeito imediato da quantidade de tec $\mathbf{i}$ do disponível é dar dimensão a fator de contenção

$$
\left(1-x_{t}\right) \text {, onde }
$$

$x_{t}$ é a quantidade de tecido doente em porcentagem.

Desta forma, quanto maior o valor da quantidade de tecido disponível ( $S W$ ) menor o valor de $x_{t}$.

A determinação da quantidade de tecido dis ponível é feita em função do tamanho padrão da lesão do sis tema em estudo, do nümero mäximo de infecções possíveis por planta, do número de plantas por unidade de área e a àrea total da cultura. Neste caso, pode-se estimar como $5 \times 10^{9}$ o nümero médio de tecido disponível para infeccões pelas ferrugens do trigo num hectare (ZADOKS, 1971).

Este tipo de abordagem pressupõe que todo tecido disponível tem a mesma ärea e a mesma probabilidade de infecção (ZADOKS, 1971). Esta simplificação não leva em 
consideração o aumento de área foliar que oçorreà medida em que às plantas crescem. Alëm disso, está demonstrado que para sistemas como Erysiphe hordey - cevada (AUST et alii, 198 1); U.phaseoli - feijão (MENDES, 1985) a idade das folhas, assim como o tipo de folha, condicionam a frequência de infecção dando, portanto, um peso relativo a cada tipo de tecido disponível.

$$
\text { Assim, numa etapa posterior, quando o mode }
$$

lo ora apresentado estiver sendo adequado a sistemas espec ficos, essas limitações envolvendo a quantidade de tecido disponível deverão ser levadas em consideração para que haja maior precisão.

os valores das taxas aparentes de infecção constantes da Tabela 8 indicam que o aumento na quantidade de tecido disponível, a partir de um certo limite, não acar reta grandes alterações na velocidade de crescimento da epi demia. Tal pode ser observado quando se constata que com $5 \times 10^{6}$ unidades de tecido disponível tem-se uma taxa aparente de infecção de 0,85 e com $5 \times 10^{13}$ unidades esta taxa é de 0,83 , ou seja, bastante pröxima uma da outra. Por outro lado, ao menor valor simulado, de $5 \times 10^{3}$ unidades corresponde uma taxa aparente de infeção de 1,04 unidade por dia, indicando que deve existir um limite de tecido disponí vel a partir do qual o sistema não é mais representativo.Es sa hipōtese jä havia sido levantada por JAMES (1974) quando. discutia a necessidade de padronização do tamanho de parçelas para que se realize avaliação de doença em campo. 
A representação gräfica dos valores simula dos constantes das Figuras 9 e 10 indicam que a evolução das epidemias se processa de forma praticamente paralela à medi da em que aumenta a quantidade de tecido sadio disponível.o efeito maior é observado no valor inöculo inicial ( $x_{0}$ ) que é dependente direto da quantidade de tecido sadio disponi vel. Há, portanto, um atraso na epidemia à medida em que au menta a quantidade de tecido sadio disponível decorrente, neste caso, do fato de que a quantidade total de tecido doen te ( $x t$ ) é uma porcentagem da quantidade total de tecido sadio (SV).

5.6. Simulação do efeito de padrões de produção de esporos com período infeccioso de 8 e 25 dias

A semelhança das simulações anteriores os valores de período infeccioso de 8 e 25 dias, assim como os do período latente de 4 dias e taxa bảsica de infecção corrigida de 16 unidades/dia, são teöricos e não correspondem especificamente a nenhum sistema patögeno-hospedeiro.

No processo epidemiolögico a existência de padrões de produção de esporos vai ter influência direta sobre a taxa bäsica de infecção corrigida (MENDES et alii, 1984), indepen dentemente do efeito do período infeccioso. Este fato pode ser observado nas Tabelas 9 e 10. 
o primeiro padrão estudado, no qual a maior parte dos esporos produzidos se concentram no inficio do período infeccioso (TENG e CLOSE, 1978; MENDES et ali $i$, 1984; MENDES, 1985), dá origem a epidemias com maior valor de taxa aparente de infecção, quando comparadas com aquelas obt das pelos outros padröes, correspondendo a 1,12 e 0,98 unidades por dia para o período infeccioso de 8 e 25 dias, res pectivamente, conforme Tabelas 9 e 10 . Explica-se este comportamento na medida em que vencido os primeiros períodos latentes o tecido infeccioso estarä produzindo grande quantidade de esporos efetivos num momento em que o fator de contenção é pequeno. Assim, a velocidade da epidemia é acelerada logo nos primeiros dias.

Situação inversa se observa com o segundo padrão estudado, que se caracteriza por concentrar a produção de esporos no final do período infeccioso. Neste caso tem-se as menores taxas de infecção aparente, conforme Tabe las 9 e 10 , correspondendo a 0,53 e 0,34 unidades por dia para 8 e 25 dias de período infeccioso, respectivamente.

o terceiro padrão, que estä baseado no modelo de produção de esporos das ferrugens tropicais (MENDES et $a$ I $i$ i 1984; MENDES, 1985) dá origem a taxas aparentes de infeção consistentemente maiores do que o quarto padrão, conforme Tabelas 9 e 10 , que nada mais é do que um valor mé 
dio constante de produção de esporos durante todo o período infeccioso. Deve-se observar, ainda, que somente este padrão não apresentou efeito do período infeccioso com a taxa aparente de infecção permanecendo em 0,84 unidade por dia, de acordo com Tabela 9 e 10. Este fato realça a importância de se estudar o padrão de produção de esporos em . modelos mais detalhados e especificamente vinculados a determinado sistema patögeno-hospedeiro.

Nas Figuras 11 e 13 pode-se observar com bastante clareza o efeito epidemiológico do segundo padrão de esporos que dä origem a retas muito afastadas do conjunto daquelas produzidas pelos outros padrões. Trata-se, ainda, de um padrão teórico, mas nada impede que um dia venha a ser descoberto, talvez até com o emprego de produtos quí-. micos.

Nas Figuras 12 e 14 observa-se principal mente o efeito do período infeccioso que, interagindo com o período latente, produz curvas com pequenas oscilações. no valor da velocidade de crescimento da doença. 


\section{CONCLUSÖES}

1. Alterações na dinâmica da epidemia, ava liada em função da taxa áparente de infecção, são observa das em decorrência de variaçoes no valor do período infeccioso enquanto este for menor ou igual ao período latente.

2. Período infeccioso de 1 dia dá origem a epidemia com crescimento descontínuo. Este fenômeno não é ma is observado à medida em que o valor do período infeccioso aumenta, uma vez que passa a haver uma sobreposição de tecidos infecciosos.

3. Alterações no valor do período latente estão inversamente relacionadas com o valor da taxa apareilte de infecçãa, numa relação aproximada de 1:0,5. 
4. Existe um limite de tecido disponível a partir do qual o modelo de simulação de epidemias, ora proposto, não ê mais representativo.

5. O valor da taxa aparente de infecção, quando comparado com aqueles gerados por outros padrões de produção de esporos, è maior se os esporos efetivos forem liberados no início do período infeccioso.

6. Os padrões de produção de esporos efeti vos devem ser incorporados aos sistemas de simulaça de doen ças. 


\section{BIBLIOGRAFIA}

ARLEN, D.D. e E.K. VAUGHAN, 1964. Effect of urediospore concentration on determination of races of Uromyces phaseoli var. phaseoli. Phythopathology. 54:336-338.

AUST, H.J; B. HAU e J. KRANZ, 1983. EPIGRAM - a simulator of barley powdery mildew. J.Plant Disease and Protection. $\underline{90}(3): 244-250$.

BATSCHELET, E. 1966. The application of mathematics to bio logical problems. Bioscience. Jan.:22-24 p. 
BERGAMIN FILHO, A. , 1983. Consequências Epidemológicas da Resistência no Sistema Coffea arabica L. - Hemizeia vastratix Berk \& BR. Piracicaba; ESALQ/USP, $111 \mathrm{p}$. (Tese de Livre - Docência).

BUTT, D.I. E D.J. ROYLE, 1974. Multiple regression analyses. In: KRANZ, J. Ed. Epidemiology of Plant Diasease, Mathematical. Analysis and Modeling. Spring-Verlag, New York. P.17-50.

CASTRO, H.A., 1983. Padronização de metodologia de inocula ção e avaliação da resistência de Eucalyplus l'heritier à ferrugem causada por Puccinia psidii WINTER. Universidade de São Paulo, Piracicaba, $116 \mathrm{p}$. (Tese de Doutoramento)

CAOKLEY SM; W.S. BOYD e R.F. LINE, 1982. Statistical models for predicting stripe rust on winter wheat in the Pacific Northwest. Phytopathology 72:1539-1542. 
COWLING, E.B. e J.G., HO'RFALL, 1978. Prologue: How disease develops in populations. In: HORSFALL, J.G. e E.B. COWLING, Ed. Plant isease an advanced treatise. Academic Press, New York. Vol. II, p. 1-15.

DAVISON, A.D. E E.K. VAUGHAN, 1964. Effect of urediospore concentration on determination of races of Uromyces phaseoli var typica. Phytopathology. 54:336-338.

DENT, J.B.e M.J. BLACKIE, 1979. Systems Simulation in Agriculture. London, Applied Science Publishers Ltd. 180p.

EVERSMEYER, M.G.; J.R. BURLEIGH e A.P. ROELFS, 1973. Equations for predicting wheat stem rust development. Phy. topathology, $63: 348-351$.

FEGIES, N.C.; B.M. MENDES e A. BERGAMIN FILHO, 1984. Pe ríodo infeccioso e produção de esporos de ferrugem (Uromy ces phaseoli var. typical em duas linhagens de feijão (Phaseolus vulgaris). In: XVII Congresso Brasileiro da Sociedade Brasileira de Fitopatologia, São Paulo, p.332. 
FRY, W.E., 1982. Principles of Plant Disease Management. New York Academic Press. 378 p.

GALLI, F. e P. de C.T. de CARVALHO, 1978. História da fi topalogia. In: GALLI, F., Coord. Manual de Fitopatologia Princípios e Conceitos, São Paulo. Ed. Agron. Ceres Ltda., Vol. I, p. 9-14.

GAUMANN, E., 1950. Principles of plant inféction. Crosby Lockwood e Son, Ltd., London, $543 \mathrm{p}$.

GROTH, J.U. e N.V.R. URS, 1982. Differences amony bean cultivars in receptvity to Uromyces phaseoli var. typica. Phytopatology.

IMHOFF, M.W.; C.E. MAIN E K.J. LEONARD, 1981. Effect of temperature, dew period and age of leaves, spores, and source pustules on germination of bean rust urediospores. Phytopathology, 71:577-583.

$\longrightarrow$ e $\longrightarrow$ 1982. Patterns of bean rust lesion size increase and spore production. Phytopathology, 72 : $441-446$. 
JAMES, W.C., 1974. Assessment of plant diseases and losses Ann. Rev. Phytopathol., 12:27-48.

JEFFERS, J.N.R., 1978. An Introduction to Systems Analysis. with ecological applications. William Clowes e Sons Lim ted. Londres. $188 \mathrm{p}$.

JEGER, M.J. 1983. Analysing epidemics in time and space Plant Pathology. $32: 5-11$.

KAMPMEIJER, P. e J.C. ZADOKS, 1977. EPIMUL, a simulator of foci and epidemies in mixtures of resistant and suscep tible plants, mosaics and multilines. Centre for Agricul tural Publishing and Documentation, Wageninger. $50 \mathrm{p}$.

KRANZ, J., 1974. Epidemiology, concepts and scope. In: Raychaudhuri S.P. e J.P. VERNA. Ed. Current Trands in. Plant Pathology, Lucknow, Lucknow University .... Botany Department p. $26-32$.

- 1979. Simulation of Epidemics Caused by Venturia incequalis (cooke) Aderh. Bul T OEPP. 9(3):235-242. 
1981. Epidemiological parameters of plant resistance. In: LAMBERTI, F.; J.M. WALLER e N.A. Van derGRAAFF (Ed.). Durable Resistance In Crops. New York. Plenum Press. $141-161 \mathrm{p}$.

—; M. MOGK e A. STUMPF, 1973. EPIVEN - ein simulator fur Apfelschorf. Vorlanfige. Mitterlung. Z. Pflanzenkr $80 \quad 181-87$.

e D.J. ROYLE, 1978. Perspectives in mathematical modeling of plant disease epidemics. In: SCOTT, P.R. e A. BAINBRIDGE. Plant Disease Epidemiology. Backwell Scientific Publications, oxford. p. 111-119.

— e B. HAU, 1980. Systems Analysis in Epidemiology. In: Ann. Rev. Phytopathol., 18: 167-83

KRAUSE, R.A. E L.B. MASSIE, 1975. Predictive sytems: modern approaches to disease control. Annual Review of Phytopathology, Polo Alto, 13:31-47. 
— - e R.A. HYRE, 1975. Blitecast: A Computurized forecast of potato late blight. Plant Dis. Reptr., 59: $95-98$

MACKENZIE, D.R., 1981. Scheduling fungicide applications for potato late. Plant Disease Reporter 65(5):394-399.

MASSIE, L.B., 1973. Modeling and similation of southern corn leaf blight descase caused by race $T$ of Helminthosporiun maydis Nisik and Miyake. Tese de Doutoramento. The Pennsylvania State Univ., University Park, Pa. 84 p.

MEHTA, Y.R., 1981. Conidial production, sporulation period and extension of lesion of Helminthosporium sativum on flag leaves of wheat. Pesquisa Agropecuäria Brasileira. $\underline{16}: 77-79$

… e J.C. ZADOKS, 1970. Uredospore prodution and sporulation period of Puccinia recondita f.sp. triticina on

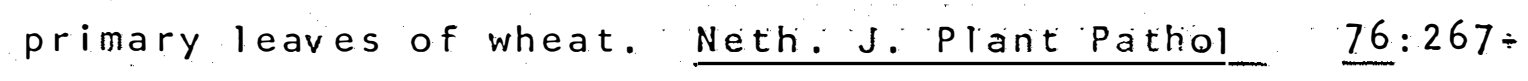
276 . 
- e S. IGARASHI, 1979. Partial resistance in wheat against Puccinia recondita: a new view on its detection and measuring. Summa Phytopathologica. 5:90-100.

MELCHING, J.S., K.R. BROMFIELD E C.H. KINGSOLVER, 1979. Infection, colonization and uredospore production on wayne soybean by four cultures of Phakopsora pachyrhizi, the cause of soybean rust. Phytopathology, 69:1262-1265.

MENDES, B.M.J., 1985. Influência da temperatura e do tipo de folha na qualificação de parâmetraś epidermológicos mono cíclicosda ferrugem do feijoeiro (Uromyces phaseoli var. typica ARTH). Universidade de São Paulo, Piracicaba, 83p. (Dissertação de Mestrado).

, N.C. FEGIES; S.B. PAIVA e A. BERGAMIN FILHO, 1984. Periodo infeccioso: um componente epidemico mal definido. Trabalho apresentado no VII Congresso Paulista de Fitopatologia, Botocatu - SP, 23 a 25 de janeiro de 1984.

MENTEN, J.0.M., 1980. Avaliação de resistência horizontal e vertical e de tolerância do feijoeiro (Phaseolus vulga ris L.) a Uromyces appendiculatus (Pers.) Ung. Universidade de São Paulo, Piracicaba, 213p. (Tese de Doutoramento). 
PAIVA, S.B.; B.M.J. MENDES; J.O.M. MENTEN E A. BERGAMIN FI LHO, 1984. GOMPERTZ: 0 modelo matemätico mais adequado para cinética de crescimento da ferrugem do feijoeiro (Uromyces appendiculatus (Pers.) UNG.) Fitopatologia Brasileira $\underline{9}(2): 333$.

PARLEVLIET, J.E., 1975. Patial resistance of barbley to leaf rust, Puccinia horiei. i. Effect of cultivar and development stage on latent period. Euphytica. 24:21-27.

' 1979. Components of resistance that reduce the rate of epidemic development. Annual Review of Phytopathology. $17: 203-222$.

— e H.J. KUIPER, 1977. Partial resistance of barley to leaf rust, Puccinia hordei. IV. Effect of cultivar and development stage on infection frequency. Euphytica. 26: $249-255$.

RABBINGE, R. e F.H. RIJSDIJK, 1983. EPIPRE: a discase and pest management system for winter wheat, taking account of micrometeorological factors. EPPO. Bull. 13(2):297305 . 
RIJSDIJK, F.H., 1975. A simulator of yellow rust of wheat. (Mimeografado). Semaine d'etude agriculture et hygiene des plantes. Facultē des Sciences Agronomiques de l'Etat etCentre de Recherches Agronomiques. B-5800-GEMBLOUX (BEL G(QUE). P. 411-418.

ROYLE, D.J. e D.J. BUTT, 1979. The place of multiple regression analysis in modern approaches to disease control. In: EPPOBull. $9(3): 155-164$.

RUSSEL, G.E., 1975. Deposition of Erysiphe graminis fsp hordei conidia on barley varieties of differing growth habit. Phytopath. Z. 84:316-321.

STANLEY, J.; K.R. BROMFIELD e C.H. KINGSOLVER, 1979. In fection, colonization, and uredospore production on wayne soybean by four culteres of Phakopsora pachyrhizi, the cause of soybean rust. Phytopathology. 69:1262-1265.

SCHOTT, K.J. E A.K. CHAKRAVORTY, 1982. The Rust Fungi. New York, London, Academic Press. 315 p. 
SHRUM, R.D., 1975. Simulation of stripe rust of wheat using Epidemic - a flexible plant disease simulation. Prog. Rept. 347. Agric. Expt. Sta.., The Pennsylvania State Univ. $81 \mathrm{p}$.

' 1978. Forecasting of Epidemics. In: HORSFALL, J.G. e E.B. COWLING., Ed. Plant Disease. An Advanced Trea tise. Academic Press, New York. Cap. 11, p.223-238.

SHANER, G.; H.W. OHM E R.E. FINNEY, 1978. Response of susceptible and slow leaf rusting wheat to infections by Puccinia recondita. Phytopathology. 68:471-475.

TENG, P.S.; M.J. BLACKIE e R.C. GLOSE, 1977. A simulation analisys of crop yield loss due to rust disease. Agricultural Systems,. 2 : $189-198$.

- e R.C. CLOSE, 1978. Effect of temperature and ure dium density on urediniospore production, latent period, and infections period of Puccinia hordei. N.Z. Journal. of Agricultural Research. 21: 287-296. 
—— M.J. BLACKIE e R.C. CLOSE, 1978. Simulation modelling of plant diseases to rationalize fungicide use. outlook on agriculture. $9(6): 273-277$.

- J.C. ZADOKS, 1980. Computer simulation of plant di seases epidemics. In: Mc Graw-Hill Yearbook of Science and Technology. New York. pp. 23-31.

TOMERLIN, J.R.; M.G. EVERSMEYer; C.L. KRAMER e L.e. BROWER, 1983. Temperature and host effects on latent and infections periods and on urediniospore production of Puccinia recondita f. sp. Trintici Phytopathology. 3: $414-419$.

VANDERPLANK, J.E., 1963. Plant Diseases. Epidemics and Control. Academic Press, New York, 349 pp.

- 1966. Something about apidemiology. The Rennsylvanha State University. (Mimeografado). p.1-7.

- 1968. Disease Resistance in Plants. New York, Lon don, Academic Press. 206 p. 
-1975. Principles of Plant 1. Nion. New York, Academic Pres. $206 \mathrm{p}$.

- 1982. Host-Pathogen Interaction in Plant Discase. Academic Press. Londres.

VIEIRA, C., 1983. Qoenças e Pragas do Feijoeiro. Viçosa, Brasil, Imprensa Universitāria - Univ.Fed.viçosa. 231 .

WAGGONER, P:E., 1974. Simulation of epidemics. In: KRANZ, J. Ed., Epidemics of Plant Diseases, Mathematical Analy sis and Modeling. Spring - Verlay, New York. p. 137159.

C J.G. HORSFALL, 1969. EPIDEM:A similator of plant discase written for a computer. Conn., Agric. Exp. Sta, New Haven. Bull. $698: 1-80$.

- — e R.J. LUKENS, 1972. EPIMAY: A simulator of southern corn leaf blight. Conn. Agric. Expt. Sta. Bull. 729: $1-84$. 
YARWOOD, C.E., 1961. Uredospore production by Uromyces plaseoli. Phytopathology. 51: 22-27.

ZADOKS, J.C., 1971. Systems analysis and the dynamics of epidemics. Phytopatology. 61: 600-610.

- e F.H. RIJSDIJK, 1972. Epidemiology and forecasting of cereal rusts, studied by means of a computer similator named EPISIM. Proccedings, Evr. Mediter $\dot{r}$. Cereal Rust Conf., Prague. $1 \mathrm{~L}$ 293-296.

- e R.0. SCHEIN, 1979. Epidemiology and Plant Disease Management. 0xford University Press, 0xford. $470 \mathrm{p}$. 
.99.

\section{APENDICE 1 - PROGRAMA EP6DMFR}

\section{1 a 115 Rotinas de entrada de dados näo transcritos}

$120 X v(M)=S v-X t(M-1): J=M-L p$

$125 C_{O}(M)=X v(M) / S v$

130 If $M=1$ Then $X I(M)=\operatorname{Md}(M) * \operatorname{Co}(M)$ : Goto 140

135 Goto 145

140 If $\mathrm{Fe}=1$ Then $X i(M)=0: X r(M)=X i(0)$ : Goto 240

$143 \operatorname{Xr}(M)=0: X i(M)=1:$ Goto 240

145 If $M=2$ And $F e=1$ Then $\operatorname{Xr}(M)=X I(1)$ : Goto 210

150 If $\mathrm{Fe}=1$ Then $\operatorname{Xr}(M)=\mathrm{Xi}(1)$ : Goto 210

165 For $Z=1$ To $\mathrm{Fe}$

170 If $Z=1$ Then Goto 185

175 If $Z=F$ Fe Then $\operatorname{Xr}(M)=X i(Z): X i(Z)=P o(Z-1)$ : Goto 195 
180 Po $(z)=X i(z): X i(z)=\operatorname{Po}(z-i)$ : Goto 195

185 Po $(Z)=X i(Z)$ : If $J<=0$ Then $X i(Z)=0$ : Goto 195

$190 \times i(Z)=X I(J)$

195 Next $Z$

200 Goto 220

210 If $J<=0$ Then $X i(i)=0$ : Goto 220

$215 \times i(1)=\times 1(J)$

220 For $Z=1$ To $\mathrm{Fe}$

$225 P i=X i(Z)+P i$

$227 V i=X i(Z): \because M d(Z)+V i$

230 Next $Z$

$235 \mathrm{Si}(M)=P i \quad: \quad X i(M)=V i * C_{O}(M): V i=0 \quad: P i=0$

240 If $J<=0$ Then $S p(M)=S p(M-1)+X$ I (M) : Goto 250

$245 S p(M)=\operatorname{Sp}(M-1)-X 1(J)+X 1(M)$

250 If $\mathrm{Sp}(M)<=0$ Then $\mathrm{Sp}(M)=0$

255 If $M=1$ Then $X t(M)=X I(M)+X i(M)+X r(M)$

$260 \times \mathrm{t}(M)=\mathrm{Xt}(M-1)+X_{1}(M)$

$265 \operatorname{Sr}(M)=\operatorname{Sr}(M-1)+\operatorname{Xr}(M)$

510 Em diante - rotinas de saídas não transcritas 
APENDICE 2 - PROGRAMA - EPSDMFR

1 a 115 Rotinas de entrada de dados não transcritos

$120 X v(M)=S v-X t(M-1): J=M-L P$

$125 \operatorname{Co}(M)=X v(M) / S V$

130 If $M=1$ Then $X I(M)=M d * C o(M)$ : Goto 140

135 Goto 145

140 If $F e=1$ Then $X i(M)=0: X r(M)=X i(0)$ : Goto 240

$143 \operatorname{Xr}(M)=0: X i(M)=1 \quad$ Goto 240

145 If $M=2$ And $F e=1$ Then $\operatorname{Xr}(M)=X I(1)$ : Goto 210

150 If $\mathrm{Fe}=1$ Then $\operatorname{Xr}(M)=X i(1)$ : Goto 210

165 For $Z=1$ To $\mathrm{Fe}$

170 If $Z=\cdot 1$ Then Goto 185

175 If $Z=F$ e Then $\operatorname{Xr}(M)=X i(Z): X i(Z)=P o(Z-1)=P o(Z-1)$ : Goto 95

$180 \operatorname{Po}(z)=X i(z): X i(z)=P o(z-1)$ : Goto 195

185 Po $(Z)=X i(Z)$ : If $J<=0$ Then $X i(Z)=0$ : Goto 195

$190 \times i(Z)=\times 1(J)$

195 Next $Z$

200 Goto 220

210 If $J<=0$ Then $X i(1)=0$ : Goto 220

$215 \times i(1)=X 1(J)$

220 For $Z=1$ To Fe

$225 P \mathrm{P}=\mathrm{Xi}(\mathrm{Z})+\mathrm{Pi}$

230 Next $Z$

$235 \mathrm{Si}(M)=P i$; $C d=C o(M) * M d: R o=C d * S i(M): X I(M)=R o$ : $P i=0$

240 If $J<=0$ Then $S_{P}(M)=S_{P}(M-1)+X I(M)$ : Goto 250

$250 S_{P}(M)=S_{P}(M-1)-X_{1}(J)+X 1(M)$

255 If $S_{P}(M)<=0$ Then $S_{P}(M)=0$ 
255 If $M=1$ Then $X t(M)=X 1(M)+X i(M)+X r(M)$

$260 \times t(M)=X t(M-1)+X I(M)$

$265 \operatorname{Sr}(M)=\operatorname{Sr}(M-1)+\operatorname{Xr}(M)$.

510 Em diante - Rotinas de saída de dados não transcritas 